\title{
Moisture Vertical Structure, Column Water Vapor, and Tropical Deep Convection
}

\author{
CHRISTOPHER E. HOLLOWAY* \\ Department of Atmospheric and Oceanic Sciences, University of California, Los Angeles, Los Angeles, California
}

\section{J. DAVID NEELIN}

Department of Atmospheric and Oceanic Sciences, and Institute of Geophysics and Planetary Physics, University of California, Los Angeles, Los Angeles, California

(Manuscript received 14 April 2008, in final form 23 November 2008)

\begin{abstract}
The vertical structure of the relationship between water vapor and precipitation is analyzed in $5 \mathrm{yr}$ of radiosonde and precipitation gauge data from the Nauru Atmospheric Radiation Measurement (ARM) site. The first vertical principal component of specific humidity is very highly correlated with column water vapor (CWV) and has a maximum of both total and fractional variance captured in the lower free troposphere (around $800 \mathrm{hPa}$ ). Moisture profiles conditionally averaged on precipitation show a strong association between rainfall and moisture variability in the free troposphere and little boundary layer variability. A sharp pickup in precipitation occurs near a critical value of CWV, confirming satellite-based studies. A lag-lead analysis suggests it is unlikely that the increase in water vapor is just a result of the falling precipitation. To investigate mechanisms for the CWV-precipitation relationship, entraining plume buoyancy is examined in sonde data and simplified cases. For several different mixing schemes, higher CWV results in progressively greater plume buoyancies, particularly in the upper troposphere, indicating conditions favorable for deep convection. All other things being equal, higher values of lower-tropospheric humidity, via entrainment, play a major role in this buoyancy increase. A small but significant increase in subcloud layer moisture with increasing CWV also contributes to buoyancy. Entrainment coefficients inversely proportional to distance from the surface, associated with mass flux increase through a deep lower-tropospheric layer, appear promising. These yield a relatively even weighting through the lower troposphere for the contribution of environmental water vapor to midtropospheric buoyancy, explaining the association of CWV and buoyancy available for deep convection.
\end{abstract}

\section{Introduction}

A number of studies indicate that moist convection is sensitive to free-tropospheric water vapor, including observational analyses (Austin 1948; Malkus 1954; Brown and Zhang 1997; Sherwood 1999; Parsons et al. 2000; Bretherton et al. 2004; Sherwood et al. 2004) and studies using cloud-system-resolving models (CSRMs; Tompkins 2001b; Grabowski 2003; Derbyshire et al. 2004). This

\footnotetext{
* Current affiliation: Department of Meteorology, University of Reading, Reading, United Kingdom.
}

Corresponding author address: Christopher E. Holloway, Dept. of Meteorology, University of Reading, Earley Gate, P.O. Box 243, Reading RG6 6BB, United Kingdom.

E-mail: chollow@ucla.edu dependence is apparently not well represented in global climate models (Derbyshire et al. 2004; Biasutti et al. 2006; Dai 2006), but sensitivity has been shown in some cases (Zhang and Wang 2006; Neale et al. 2008; Bechtold et al. 2008). Deficiencies in the positive feedback between free-tropospheric moisture, cumulus convection, and large-scale dynamics may also contribute to poor global climate model simulation of multiscale convective organization, including intraseasonal variability associated with the Madden-Julian oscillation (Grabowski 2006). Regions where drier tropospheric air flows into convection zones tend to exhibit sensitivity to changes associated with teleconnections and global warming. These regions also exhibit disagreement in simulated precipitation among different models, which is potentially associated with dependence on tropospheric moisture (Neelin et al. 2003; Dai 2006; Neelin et al. 2006; 
Lintner and Neelin 2008). Because precipitation processes in climate models are very sensitive to the method of convective parameterization (Slingo et al. 1996), it is of interest to investigate the relationship between tropospheric moisture and precipitation in observations and its representation in convective parameterizations.

A few recent studies have illustrated an empirical relationship between tropical column water vapor (CWV), scaled by some measure of free-tropospheric temperature, which does not change very much in the deep tropics, and precipitation, including a sharp increase or "pickup" of conditionally averaged precipitation at sufficiently high CWV (Bretherton et al. 2004; Peters and Neelin 2006). In the present study, we investigate the vertical structures of water vapor variability at Nauru Island in the western equatorial Pacific. One goal is to better understand the vertical distribution of the moisture variance associated with $\mathrm{CWV}$, a metric easily available from satellite data, and to connect the CWVprecipitation relation to buoyancy computations for entraining plumes. Another motivation is to investigate the main vertical structures of water vapor perturbations, providing insight for intermediate-complexity models that represent water vapor with one or a few vertical structures, such as the quasi-equilibrium tropical circulation model (QTCM; Neelin 1997; Neelin and Zeng 2000). Although we focus on radiosondes and gauge data from a single island, the relationships among CWV, plume buoyancy, and precipitation at these scales can inform both stochastic representations of convection and other parameterizations incorporating the effects of subgridscale plume interactions, including those that attempt to account for the variability of environmental fields within each grid box. A comparison of these point data to larger-scale satellite data is presented in appendix A.

After characterizing the vertical structure of water vapor and its relationship to average precipitation and CWV in section 3 , we turn to the effects of different environmental profiles of moisture on simple plume models of convection in section 4. Analysis in terms of an entraining plume (e.g., Raymond and Blyth 1992; Brown and Zhang 1997; Jensen and Del Genio 2006) is used to connect the increased buoyancy of entraining plumes in moist environments with the sharp pickup of average precipitation at high CWV (and a corresponding increase in average cloud-top height is shown in appendix B). We also investigate the role of subcloud layer moistening versus free-tropospheric moistening on entraining plume buoyancy. The sensitivity of the results to assumptions of entrainment profiles and microphysics in section 5 provides insight into the challenges of incorporating environmental humidity in convective parameterizations. Weighting functions for environmen- tal variables implied by different entrainment profiles, together with the constraint provided by matching the onset of deep convective buoyancy to the pickup in precipitation, are then used to explain why column water vapor provides a good variable for examining deep convective onset.

\section{Data}

The Department of Energy's Atmospheric Radiation Measurement (ARM) Program (Stokes and Schwartz 1994) maintains a climate observation site at Nauru Island $\left(0.5^{\circ} \mathrm{S}, 166.9^{\circ} \mathrm{E}\right.$; Mather et al. 1998). We have analyzed radiosonde temperature and moisture data and optical gauge surface precipitation from 1 April 2001 to 16 August 2006. The radiosonde data have been interpolated onto 5-hPa levels. The uncertainty of the Vaisala (RS80, RS90, and RS92) radiosondes is approximately $0.5^{\circ} \mathrm{C}$ for temperature and $5 \%$ for relative humidity, although in the upper troposphere (above $500 \mathrm{hPa}$ ) relative humidity uncertainties can be much larger (Westwater et al. 2003). The main observations occur twice a day, at 0000 and 1200 UTC, with occasional sondes around 0230 and 1430 UTC.

The precipitation rate is measured at 1-min intervals by an optical gauge with $0.1 \mathrm{~mm} \mathrm{~h}^{-1}$ resolution and $0.1 \mathrm{~mm} \mathrm{~h}^{-1}$ uncertainty. For comparison with the radiosondes, a 1-h average rain rate has been computed, centered at the launch time of each radiosonde. Because the sonde takes about $45 \mathrm{~min}$ to rise through the troposphere, this averaging window should give a good characterization of the precipitation conditions in the air mass through which the sonde rises. Time averaging also helps reduce the precipitation measurement noise inherent in the use of a single gauge; averaging over many hourly events, as is done in the analyses of this study, further reduces this noise.

The sonde pressure, temperature, and humidity data had a basic quality check at ARM and have been further constrained to be within reasonable ranges; the lowestaltitude sonde data have also been checked for agreement with ARM surface data. In total, 3491 sondes have been retained for the complete analysis (with 200 additional sondes containing acceptable data at some levels included in the water vapor variability analyses). The radiosonde versions analyzed in this study are not thought to have much dry bias, which characterized earlier Vaisala sonde versions (B. M. Lesht 2007, personal communication). The sonde CWV values compare fairly well with 1-h averages of microwave radiometer values, with a correlation coefficient of 0.92 . A slight tendency for the sondes to be moister than the radiometer at high CWV likely occurs because the radiometer 
cannot operate during rainfall and may have difficulties when cloud water is large. Appendix A includes a comparison of CWV between the radiosondes and Tropical Rainfall Measurement Mission (TRMM) Microwave Imager (TMI) satellite data over Nauru at three averaging resolutions, showing good agreement through the range of available data. Appendix B shows an analysis of cloud-top height data from the ARM Active Remotely Sensed Cloud Locations (ARSCL) product (Clothiaux et al. 2000) from April 2001 through January 2005.

\section{Characterizing the vertical structure of moisture}

An important step in investigating the vertical structure of the transition to deep convection is characterizing the vertical structure of moisture variations as a whole. This endeavor is more complicated than the analogous problem for tropical temperature perturbation structures, which tend to follow reversible moist adiabats and are smoothed in the horizontal by gravity waves, at least in the free troposphere on large enough space and time scales (e.g., $\mathrm{Xu}$ and Emanuel 1989; Holloway and Neelin 2007). Water vapor has smaller spatial uniformity than temperature in the tropics and is more locally influenced by evaporation, precipitation, and advection. Here we investigate the vertical variability of water vapor at Nauru and relate this to CWV, which in turn is related to precipitation.

\section{a. Effect of precipitation on moisture structure}

Profiles of specific humidity $q$ conditionally averaged on precipitation (Fig. 1) reveal that it is mainly freetropospheric moisture, rather than boundary layer moisture, that increases with increasing rainfall. The spread among the curves is larger than the maximum confidence interval, indicating that the separation of the mean specific humidity at many tropospheric levels by average precipitation is real. Note that the bins double in width with increasing precipitation and that most of the sondes fall into the first bin (see caption for bin counts), which is basically nonprecipitating, so that the $q$ profile in that bin is actually fairly representative of the mean profile overall. In the highest precipitation bin, there is actually a decrease in the subcloud layer moisture compared to the other bins, probably due to subsaturated downdrafts forming cold pools (see section 3e).

Figure 1 can be compared to analyses of monthly and daily averages of specific humidity profiles from radiosondes conditionally averaged on precipitation in Bretherton et al. (2004, their Figs. 9 and 10a). Although their monthly means from many long-term tropical radiosonde stations do not show much difference be-

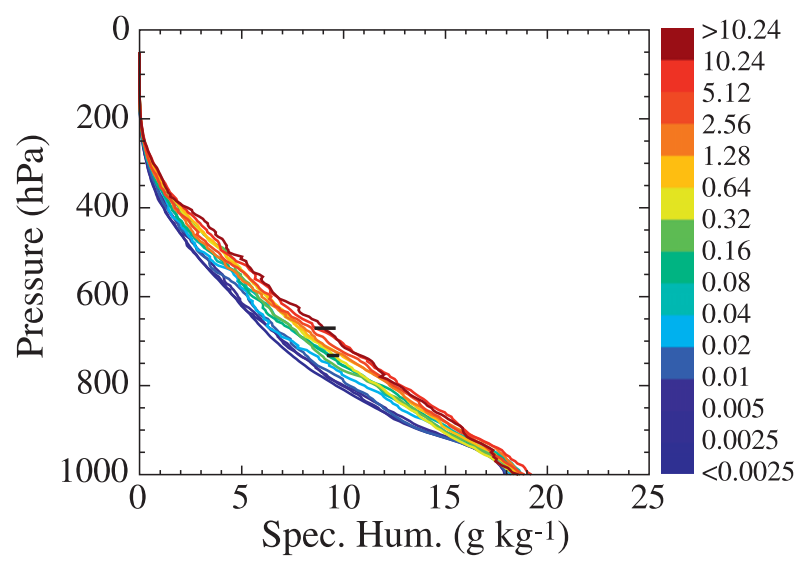

FIG. 1. Specific humidity $\left(\mathrm{g} \mathrm{kg}^{-1}\right)$ profiles conditionally averaged on 1 -h average precipitation rate in $\mathrm{mm} \mathrm{h}^{-1}$ (color bar). Bin counts from the lowest to highest precipitation range are 2805,93 , 90, 59, 32, 40, 36, 49, 47, 43, 44, 30, 21, and 11. Horizontal bars indicate the maximum, as well as a representative, \pm 1 standard error of the mean (standard deviation divided by the square root of the sample number) range.

tween spread at free-tropospheric levels and spread in the boundary layer, their 2 months of daily TRMM Kwajalein Experiment (KWAJEX) sondes do show variability similar to that in these $5 \mathrm{yr}$ of ARM twicedaily data, although their values are a little lower. Concurrent work by Nuijens et al. (2009) for trade cumulus conditions near Barbuda finds a similar relationship between lower-free-tropospheric humidity and precipitation.

\section{b. Leading vertical structure and relation to column water vapor}

Two recent studies have investigated a statistical link between CWV and precipitation using satellite data. Bretherton et al. (2004) show that on daily and monthly scales precipitation increases roughly exponentially with CWV. Peters and Neelin (2006) find that precipitation, conditionally averaged by CWV over many individual events, tends to increase slowly up to some critical value and then rapidly increase above that. This kind of relationship can be detected in these ARM data as well, as discussed below in section 3c. An important question, however, concerns how the variance of $\mathrm{CWV}$ is distributed over different vertical levels.

Figure 2a shows the results of principal component (PC) analyses (using the covariance method) performed on each level of $q$ from 1000-200 hPa for all available sondes and for a much smaller "high precipitation" subset of sondes that occur within $\pm 3 \mathrm{~h}$ of 1 -h precipitation values greater than $2.56 \mathrm{~mm} \mathrm{~h}^{-1}$ (red and blue lines, respectively). The solid lines show the variance explained by the first principal component (PC 1) for 


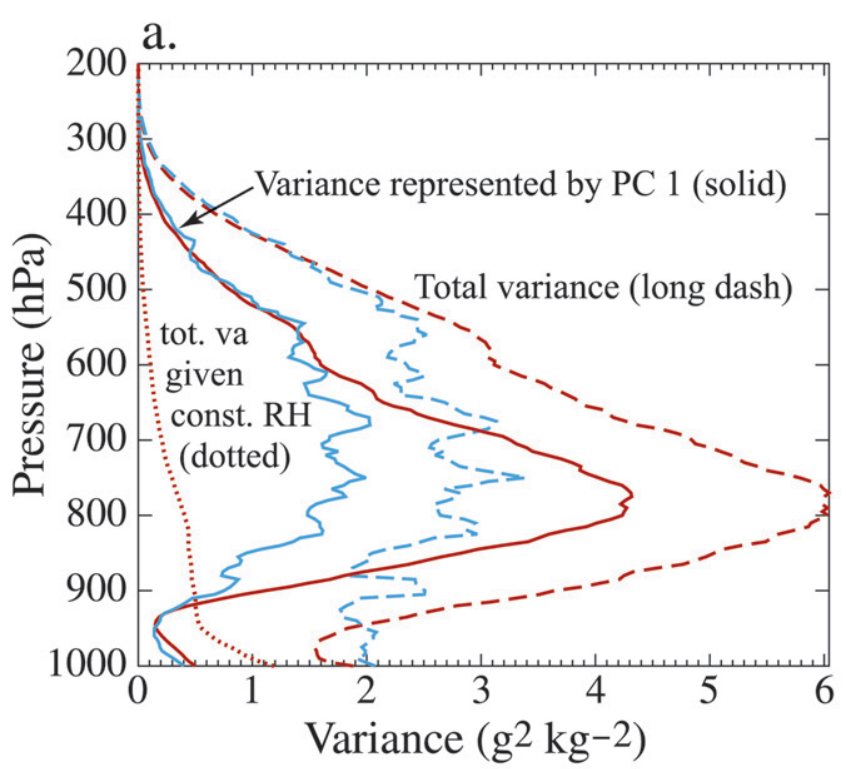

b.
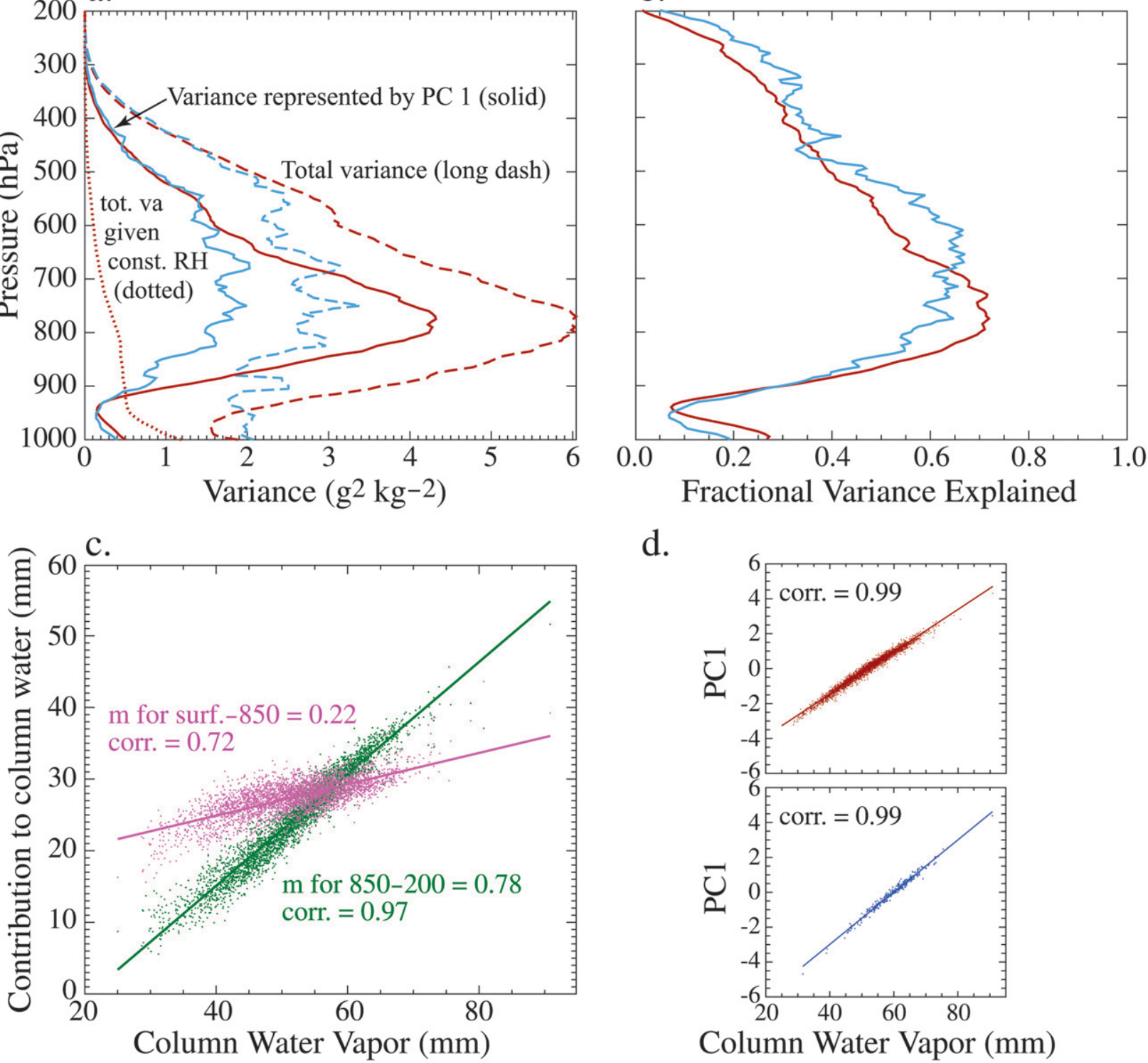

d.

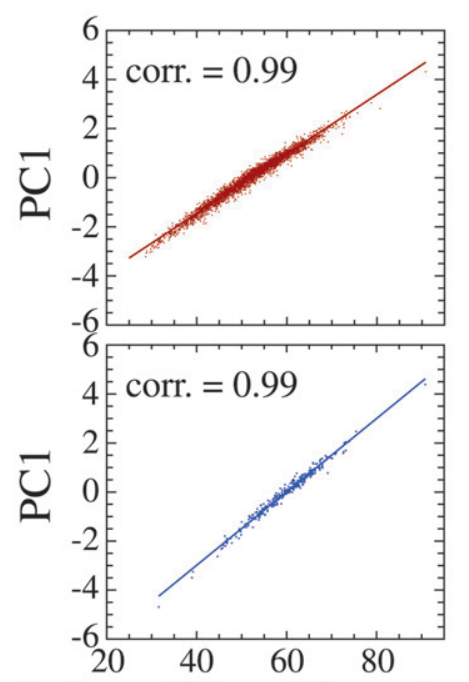

Column Water Vapor (mm)

FIG. 2. (a) Variance of specific humidity $\left(\mathrm{g}^{2} \mathrm{~kg}^{-2}\right.$ ) for all sondes (red) and for sondes within $\pm 3 \mathrm{~h}$ of the highest precipitation averages (blue). Long-dashed lines show total variance; solid lines show variance explained by PC 1 at each level. The dotted red line shows total variance at each level of a hypothetical specific humidity field derived only from temperature and a fixed relative humidity profile (taken from the mean of all original sonde relative humidity). (b) Fractional variance explained by PC 1. (c) Scatterplots and linear regressions of the integrated contribution to column water ( $\mathrm{mm}$ ) from the surface to $850 \mathrm{hPa}$ (magenta) and from $850-200 \mathrm{hPa}$ (green) vs the column water vapor. (d) Regressions and correlations of PC 1 vs column water vapor (top) for all sondes and (bottom) for sondes within $\pm 3 \mathrm{~h}$ of the highest 1-h precipitation.

the two analyses, whereas the long-dashed lines show the total variance of $q$ at each level. The PC loadings (or EOFs, not shown) are the square roots of the solid curves and are all positive for these cases. These principal components represent $53 \%$ and $49 \%$ of the total variance for all sondes and for the high precipitation sondes, respectively. In both analyses, the second principal component represents a much smaller fraction of the variance and is not well separated from the other higher principal components. The dotted red line shows total variance at each level of a hypothetical specific humidity field derived only from temperature and a fixed relative humidity profile (taken from the mean of all original sondes). This shows that observed changes in temperature alone, assuming constant relative humidity, could account for only a small amount of the total 
moisture variances. This is generally expected in the tropics for these short time scales and appears to be particularly true at this western Pacific location. The corresponding curves for sondes stratified by time of day (not shown) are not significantly different from these curves except for an approximately $\pm 25 \%$ difference at the lowest levels for the dotted red line.

The solid curve can be divided by the dashed curve in each case to get the fractional variance represented by PC 1 at each level, shown in Fig. 2b. The square roots of these profiles (the correlation coefficients between PC 1 and $q$ at each level; not shown) line up fairly well with correlations between CWV and water vapor mixing ratio found for an average over soundings from many research vessel cruises in the tropics (see Fig. 5a in Yoneyama 2003).

The most striking feature of these figures is the large peak in the lower troposphere for both total variance and fractional variance represented by PC 1 . It makes sense that variance decreases upward in the upper troposphere because increasingly colder temperatures limit the saturation specific humidity and therefore the variance of water vapor. Smaller total variance at boundary layer levels is in agreement with many previous studies, suggesting that boundary layer $q$ is tied fairly closely to SST, whereas free-tropospheric $q$ can vary greatly because of processes such as dry air intrusions and advection from convective regions (e.g., Liu et al. 1991; Yoneyama 2003). However, the small fractional variances in the boundary layer shown in Fig. $2 b$ reveal that the maximum shared variance (PC 1 in each case) is dominated by the lower troposphere even more than would be predicted based on a fixed fraction of the total variance.

Figure $2 \mathrm{c}$ shows the contributions to the CWV variance from the vertically integrated boundary layer (surface-850 hPa) and free-tropospheric (850-200 hPa) water vapor. Even though the boundary layer contains a mean vertically integrated contribution to column water of $27.5 \mathrm{~mm}$, slightly higher than the corresponding value of $24.5 \mathrm{~mm}$ in the free troposphere, it is clear from the correlations and regressions (which add to 1 , since these two layers add up to give $\mathrm{CWV}$ ) that a large majority of the total column variance is explained by the freetropospheric layer.

Figure $2 \mathrm{~d}$ confirms that for each of these cases, the first principal component shown in Figs. 2a,b is almost perfectly correlated with $\mathrm{CWV}$, in agreement with Liu et al. (1991). Therefore, the solid curves in Fig. 2a represent the variance at each level explained by CWV, which as a whole represents approximately $50 \%$ of the total variance in each case as shown in the figure. Applying the above findings for PC 1 , this means that freetropospheric levels contribute the great majority of the total CWV variance to an even greater extent than would be expected by simply taking a fixed fraction of the total variance at each level, and despite the slightly larger mean vertically integrated moisture contained below $850 \mathrm{hPa}$. Not only do free-tropospheric levels have larger $q$ variances than boundary layer levels, they also vary together to a much greater extent than they share variance with boundary layer levels (as shown by the high PC-1 loadings in the lower free troposphere). This implies that to a very good approximation, CWV could be represented by a free-tropospheric vertically integrated $q$ added to a constant mean boundary layer value (or even better, a boundary layer value that is a linear function of the free-tropospheric value).

\section{c. Free-tropospheric versus boundary layer vertically integrated water vapor: Relationship to moisture structure and precipitation}

To illustrate the vertical profiles of moisture associated with different amounts of column water, and specifically with the transition to high precipitation, we conditionally average sonde profiles on water vapor integrated over three different vertical layers. Figure $3 a$ shows specific humidity profiles conditionally averaged on total CWV (the bins are equal width except for the two outer bins, as shown on the color bar). Although there is some spread in the boundary layer, the largest spread occurs around $800 \mathrm{hPa}$, consistent with Fig. 2a.

For CWV bins below about $50 \mathrm{~mm}$, the subcloud layer (below $950 \mathrm{hPa}$ ) is more vertically constant and more sharply distinguished from the troposphere, as expected for stable subsidence conditions. Much of the tropospheric variability in these bins - specifically, the incremental decrease in $q$ with CWV in the layer 850-400 $\mathrm{hPa}$-appears consistent with subsidence (along complex trajectories) altering air that had once been closer to saturation (e.g., Sherwood et al. 2006). Figure 3a also fits well with previous descriptions of dry intrusions in the free troposphere, which can suppress deep convection for over a week while shallow convection slowly moistens the lower troposphere (Numaguti et al. 1995; Mapes and Zuidema 1996; Brown and Zhang 1997; DeMott and Rutledge 1998; Parsons et al. 2000).

Much of the variability occurs at the lower end of the CWV range, as discussed above; this is not seen for the humidity profiles conditionally averaged on precipitation shown in Fig. 1. This is expected because the lowest precipitation bin in that figure contains the vast majority of sondes, probably including mostly sondes with middle and drier CWV values as well as some higher values. This association of near-zero precipitation with the lower half of CWV bins is confirmed by Fig. 3b, which shows precipitation conditionally averaged on the same CWV bins as in Fig. 3a. 

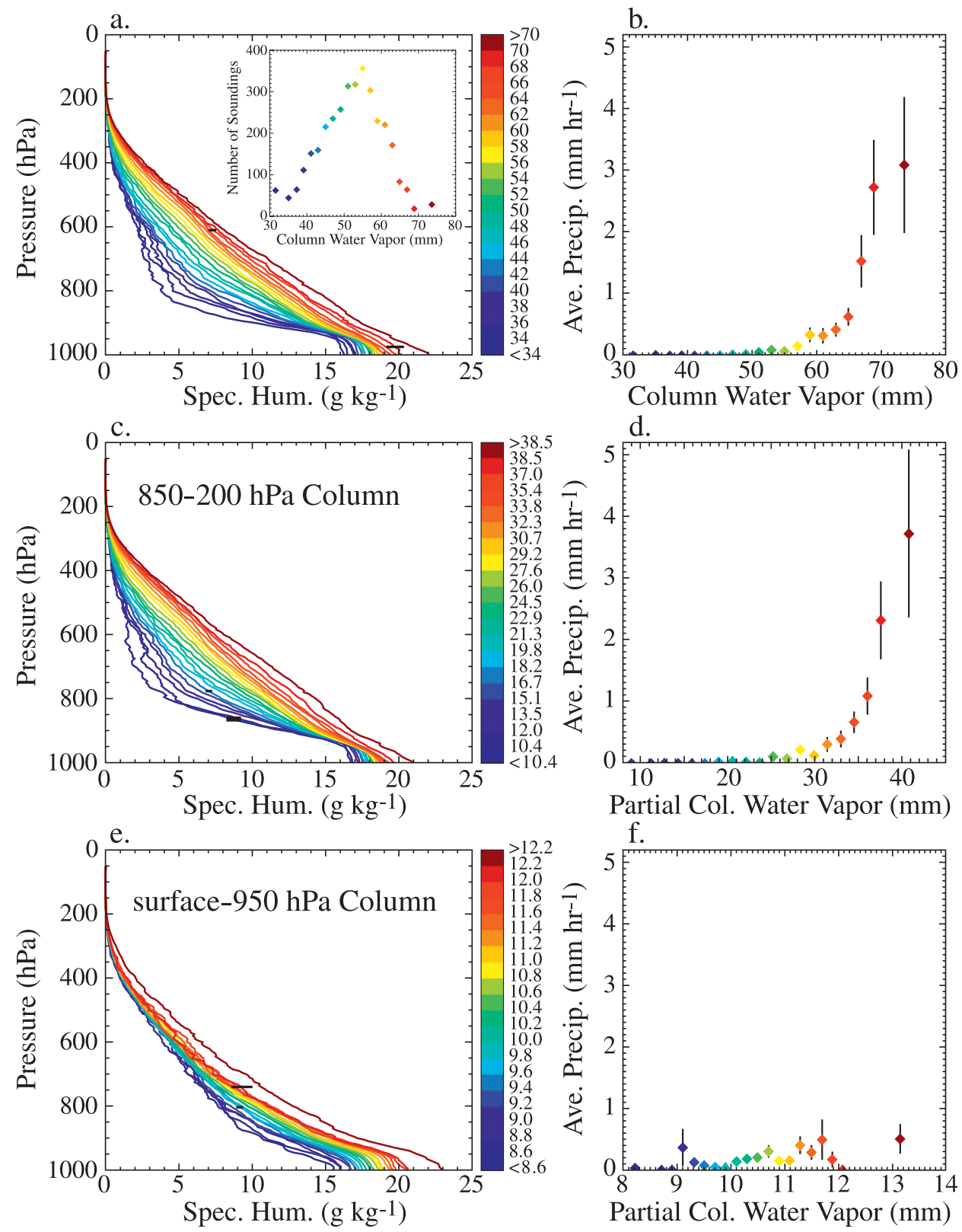

FIG. 3. Specific humidity $\left(\mathrm{g} \mathrm{kg}^{-1}\right)$ profiles and 1-h average precipitation rates, respectively, conditionally averaged on (a),(b) total column water vapor in $\mathrm{mm}$ (color bar), (c),(d) column water integrated from 850 to $200 \mathrm{hPa}$ (color bar), and (e),(f) column water integrated from the surface to $950 \mathrm{hPa}$ (color bar). Vertical bars on precipitation bin means represent \pm 1 standard error. Horizontal bars indicate limits of the maximum, as well as a representative, standard error range. Inset for (a) shows number of sondes for total CWV bins plotted against each bin's average value.

There is a sharp pickup of precipitation above approximately $66 \mathrm{~mm}$ CWV in Fig. 3b. This jump is significant, as indicated by the vertical bars representing \pm 1 standard error. The sharp pickup of precipitation roughly agrees with Peters and Neelin (2006) in both CWV value and shape, although the small number of sondes in the bins with highest CWV (illustrated by the inset in Fig. 3a) makes it impossible to confirm whether the curve follows a power-law function as observed in that study. As noted in Neelin et al. (2008) and in the next subsection, these upper CWV bins do not correspond to fully saturated columns; in section 4, correspondence of the pickup to the onset of conditional instability of entraining plumes will be argued. The 

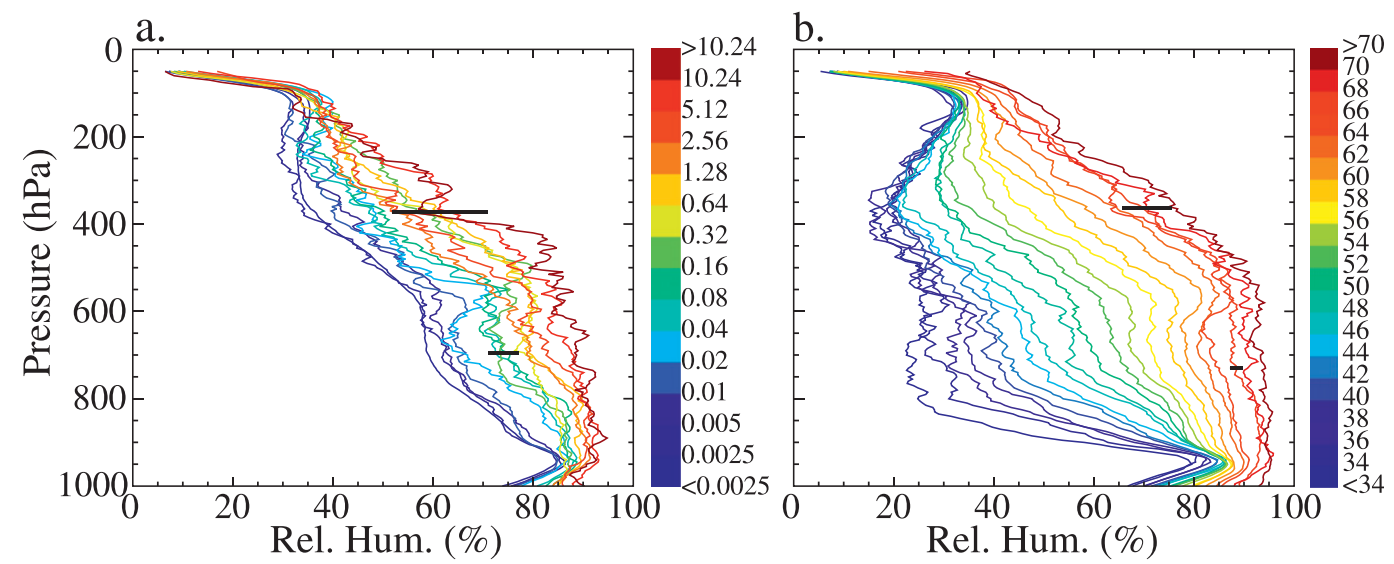

FIG. 4. Relative humidity (\%) profiles conditionally averaged on (a) the 1-h average precipitation rate in $\mathrm{mm} \mathrm{h}^{-1}$ (color bar) and (b) column water vapor in $\mathrm{mm}$ (color bar). Horizontal bars indicate limits of the maximum, as well as a representative, standard error range below $150 \mathrm{hPa}$.

feasibility of observing the sharp increase in precipitation does depend on sufficient spatial and temporal resolution-for instance, daily mean values exhibit a general increase of precipitation with CWV in Bretherton et al. (2004), but their CWV range does not reach 65 $\mathrm{mm}$. Both the initial slow increase of precipitation below $60 \mathrm{~mm}$ CWV and the sharp pickup above $66 \mathrm{~mm}$ also coincide with transitions to greater cloud-top height (see appendix B).

When the specific humidity profiles and precipitation are conditioned on just the free-tropospheric column water $(850-200 \mathrm{hPa}$, with bin edges chosen to correspond as much as possible to those for the total CWV), the results are similar to those found with the total CWV. This is expected; section $3 b$ showed that lowerfree-tropospheric $q$ variance dominates CWV variance. Indeed, Fig. 3c shows even less variance in the boundary layer, which of course follows from the use of a freetropospheric layer for the conditional averaging. The precipitation averages in Fig. 3d actually seem to have an even smoother pickup (of similar shape to that in Fig. 3b).

Figures $3 \mathrm{e}$ and $3 \mathrm{f}$ confirm that the subcloud layer (up to $950 \mathrm{hPa}$ ) is much less related to CWV. Little of the free-tropospheric variability illustrated for $\mathrm{CWV}$ in Fig. 3a is captured in Fig. 3e. The precipitation averages in Fig. 3f perhaps suggest a slight noisy increase in precipitation with subcloud layer moisture, but the values are much smaller. This relationship has implications for intermediate-complexity models such as the QTCM. A single vertical degree of freedom in moisture indeed captures much of the effect on precipitation, but its variance is primarily in the free troposphere. Modeling can thus benefit from two degrees of freedom in the vertical (cf. Neggers et al. 2007; Sobel and Neelin 2006) to allow the free troposphere to be separated from the boundary layer, which tends to be closely tied to surface conditions.

\section{d. Relative humidity structure}

A question that naturally follows from Figs. 1-3 is the extent to which the higher values of specific humidity are approaching saturation. Figure 4 a shows that for the highest precipitation bins, the average relative humidity ranges from $85 \%$ to $90 \%$ in the lower and middle troposphere. The lowest precipitation bin, which contains the vast majority of sondes (and is therefore a much smoother curve), is at the lowest end in relative humidity. However, there is much more of a spread in relative humidity when profiles are conditionally averaged on CWV, as shown in Fig. 4b. The relative humidity is around $95 \%$ for the very highest bins from $900 \mathrm{hPa}$ through about $600 \mathrm{hPa}$, and there is also a large amount of variability among the bins at these levels. Clearly, the specific humidity variability shown in Fig. 3a corresponds to large changes in relative humidity rather than changes in temperature at constant relative humidity.

\section{e. Precipitation lag-lead analysis}

An important question regarding the association between CWV and precipitation is whether observations can supply an indication of causality. There are reasons to expect feedbacks in both directions. Convection can moisten the column via moisture convergence, detrainment, and evaporation (although on a larger scale convection is a net sink of moisture). A likely mechanism by which increased lower-tropospheric moisture could play a causal role in enhancing convection-by allowing entraining plumes to maintain higher buoyancy (Stommel 1947; Brown and Zhang 1997; Sherwood 1999; Raymond 2000; Tompkins 2001b; Grabowski 2003)—is 
investigated in sections 4 and 5. Derbyshire et al. (2004) found that effects of lower tropospheric moisture on buoyancy via entrainment appear to be quite important compared to other mechanisms involving downdrafts and cold pools (e.g., Raymond 1997; Tompkins 2001a), although these and radiative mechanisms (Mapes and Zuidema 1996) may also play a role.

A lag-lead analysis on precipitation versus CWV can help strengthen or weaken a causality argument. Sherwood and Wahrlich (1999) found that CWV from sondes near satellite-detected convective systems was elevated within $3 \mathrm{~h}$ of convective onset, with peak CWV occurring just after onset or during ongoing convection. Mapes et al. (2006) used Tropical Ocean Global Atmosphere Coupled Ocean-Atmosphere Response Experiment (TOGA COARE) data to show that regressions of radiosonde $q$ values on gauge precipitation exhibit positive moisture anomalies between 700 and $800 \mathrm{hPa}$ several hours before and near the time of maximum rainfall, whereas anomalies tend to be reduced at these vertical levels (and increased at mid to upper levels) several hours after precipitation. These studies suggest that CWV is not just associated with heavy rainfall itself; rather, high CWV often precedes precipitation, typically in the form of mesoscale convective clusters or larger-scale features.

Figure 5 shows profiles of average specific humidity anomalies (taken as differences from the highly populated bin with precipitation less than $0.0025 \mathrm{~mm} \mathrm{~h}^{-1}$ ) for precipitation above $2.56 \mathrm{~mm} \mathrm{~h}^{-1}$ lagging and leading the radiosonde by up to $3 \mathrm{~h}$. The black curve is the same anomaly centered around the rainfall.

In general, Fig. 5 shows that $q$ is highest at the time of precipitation and slightly lower before and after. The standard error bars for the $q$ plots give an indication that the lag-lead curves are significantly different from the no-lag curve at most levels, although not necessarily from each other. There is some indication that levels below $800 \mathrm{hPa}$, and especially below $900 \mathrm{hPa}$, are moister before and during rainfall than afterward, possibly because of cold pools. In the upper troposphere above $400 \mathrm{hPa}$, there is slightly more moisture during and after rainfall. These lag-lead differences at different levels are consistent with previous data analyses (Sherwood and Wahrlich 1999; Sobel et al. 2004; Mapes et al. 2006).

These results do not support the idea that heavy rain is directly causing the increase in $q$ in the lower troposphere (although there is a peak in $q$ at nearly all levels associated with the rain event itself). However, the main finding is that the atmosphere remains moist for all the leads and lags. Indeed, a comparison with Figs. 2a,b suggests that the main mode of variance for $q$ is captured by all of the curves in Fig. 5 regardless of pre-

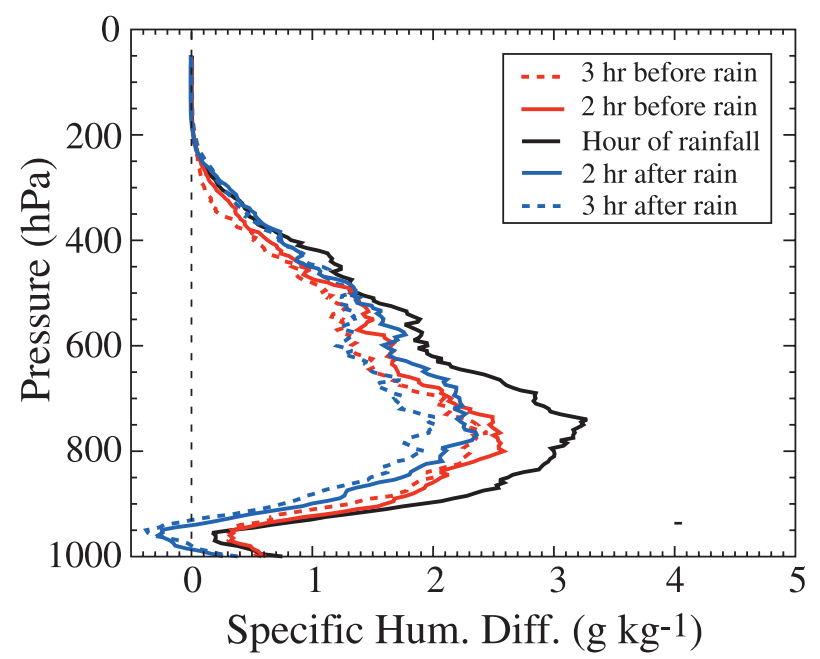

FIG. 5. Specific humidity anomalies (taken as differences from the highly populated bin with precipitation less than 0.0025 $\mathrm{mm} \mathrm{h}^{-1}$ ) for precipitation above $2.56 \mathrm{~mm} \mathrm{~h}^{-1}$ lagging (before rain) and leading (after rain) the radiosonde by up to $3 \mathrm{~h}$. The horizontal bar on the right shows the maximum standard error range.

cipitation lag. In other words, within $6 \mathrm{~h}$ centered around heavy precipitation the atmosphere has already been moistened to near-maximum levels.

A likely interpretation of these results is that high CWV tends to persist for relatively long times, thus increasing the chance of precipitation during those times. This is supported by an analysis of microwave radiometer and gauge data from Nauru showing that CWV has much higher characteristic autocorrelation times than precipitation or cloud water (Neelin et al. 2008). These findings also seem compatible with suggestions that much of the variance in water vapor in the tropics may be due to dry air intrusions from the midlatitudes or subtropics that moisten relatively slowly, as mentioned in section 3c. To better look at possible physical mechanisms responsible for the relationship between CWV and precipitation, in the next section we turn our attention to entraining plume analyses.

\section{Impact of tropospheric moisture on buoyancy: Basics}

\section{a. Moist stability profiles}

Figure 6 shows $\theta_{e}$ and $\theta_{e s}$, calculated reversibly following Emanuel (1994), for all the bins shown in Fig. 3a above $50 \mathrm{~mm}$ CWV. (Because we are mainly interested in the changes that occur around and above the precipitation pickup, which occurs around $67 \mathrm{~mm}$ for these data, we have grouped all of the values below $50 \mathrm{~mm}$ into only two wide bins, which therefore have proportionately higher counts). An approximate measure 


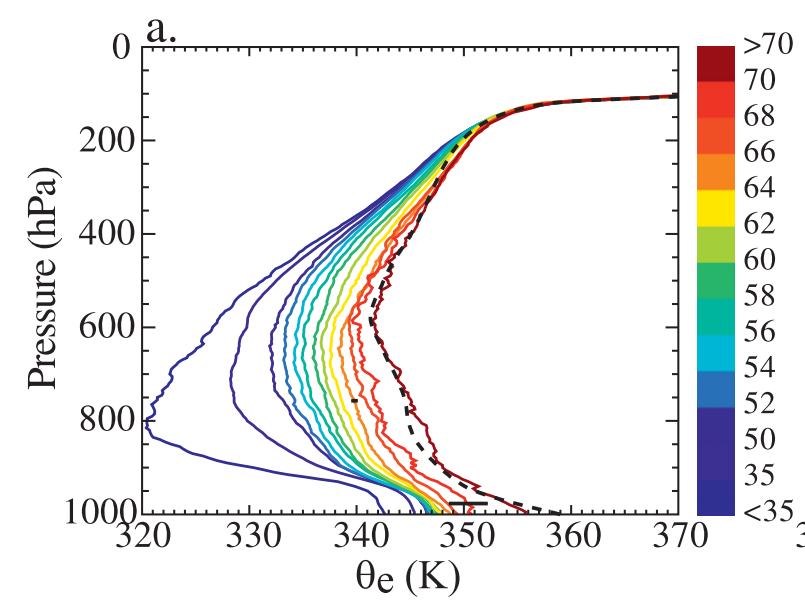

b.

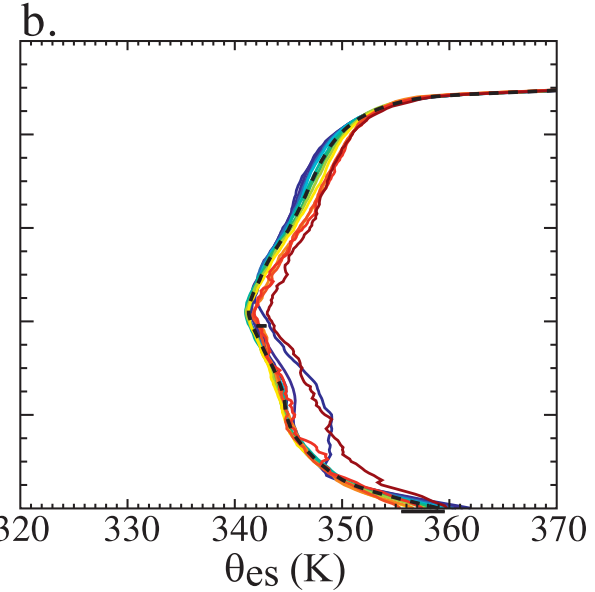

FIG. 6. Profiles of reversible (a) $\theta_{e}(\mathrm{~K})$ and (b) $\theta_{e s}(\mathrm{~K})$. These are conditioned on column water vapor in mm (color bar). The dashed black line, reproduced in each panel, is the bin-count-weighted mean $\theta_{e s}$ profile for all bins greater than $50 \mathrm{~mm}$. Horizontal bars indicate limits of the maximum, as well as a representative, standard error range below $150 \mathrm{hPa}$.

(though one that does not account for the effect of condensate on virtual temperature) of parcel buoyancy and convective available potential energy (CAPE) is to draw a vertical line upward from $\theta_{e}$ at the parcel starting level. Where this line crosses the $\theta_{\text {es }}$ curve is roughly the level of free convection (LFC) of the unmixed parcel; the area to the left of the vertical line and to the right of the $\theta_{e s}$ curve is roughly proportional to CAPE. It is clear that for the highest CWV bins, there are potentially buoyant parcels starting from many lower-tropospheric levels (up to $800 \mathrm{hPa}$ ), assuming they can be lifted to their LFCs. This will be discussed further below as it relates to the effect of entrainment at different levels on parcel buoyancies. It is also interesting that the highest $\theta_{e}$ profile is so close to the average $\theta_{e s}$ bin, indicating that the profiles in the highest CWV bin are close to the saturation specific humidity level of the typical atmospheric temperature profile.

\section{b. Buoyancy contribution for simple entraining plumes}

Under the hypothesis that buoyancy effects govern the empirical relationships described above, we calculate the buoyancy perturbation profiles for plumes rising from the subcloud layer under various mixing assumptions. Figure 7a shows the resulting virtual temperature perturbations using original sonde data for a hypothetical parcel raised from $1000 \mathrm{hPa}$ that simply conserves total water specific humidity $q_{t}$ and liquid water potential temperature $\theta_{l}$, with no entrainment or loss of condensate. These individual sonde perturbation profiles have been conditionally averaged by CWV, with bin spacing as in Fig. 6.
Figure 7a shows that without mixing, 1000-hPa parcels easily become buoyant for nearly all the bins. (The CAPE values, obtained by integrating the positive part of these curves times the gas constant over log pressure, range from near 0 to around $1800 \mathrm{~J} \mathrm{~kg}^{-1}$ ). This does not correspond to the sharp increase in average precipitation shown for the three rightmost bins as seen in Fig. 3b, which have the same bin edges as in Fig. 7.

We thus proceed to quantify how various assumptions for entrainment affect the correspondence between the pickup in precipitation and the onset of convective instability as a function of CWV. We begin with a constant isobaric linear mixing with coefficient $\chi$ of $0.1 \%$ per hPa, following Brown and Zhang (1997):

$$
r_{k}=\left(1-\chi_{k-1}\right) r_{k-1}+\chi_{k-1} \tilde{r}_{k-1},
$$

where $r$ is a conserved variable and $\tilde{r}$ its environmental value, and $k$ denotes pressure level if $\chi$ varies.

Brown and Zhang (1997) tuned $\chi$ to capture cloudtop height in TOGA COARE data. With this mixing, the virtual temperature perturbation profiles (Fig. 7b) show a distinctive (and statistically significant) separation around the same bin in which there is a sharp increase in precipitation in Fig. 3b. In other words, the three highest CWV bins, which have much higher precipitation, show distinctively larger buoyancy perturbations than their neighbors between about 850 and $150 \mathrm{hPa}$, with this separation growing larger at higher levels when this slow constant mixing has had maximum effect. These are also the only three CWV bins that are still positively buoyant above $400 \mathrm{hPa}$.

To show the relative importance of subcloud versus free-tropospheric moisture on plume buoyancy, Figs. 7c,d 

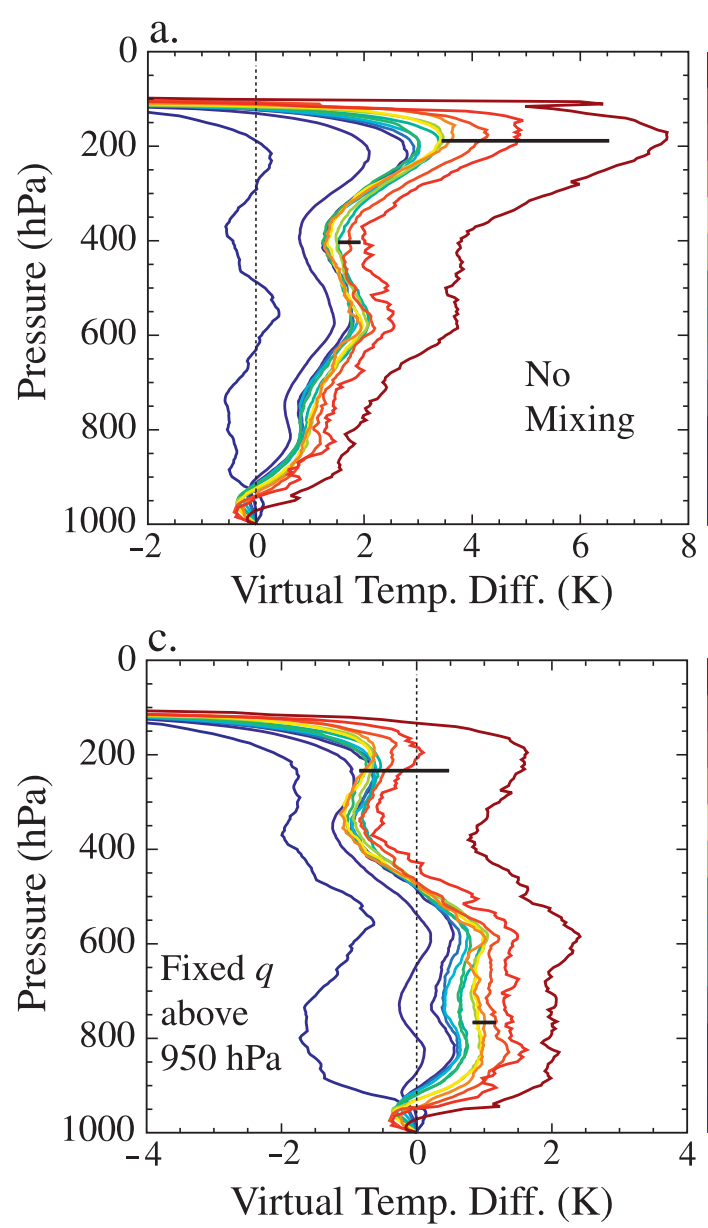

b.

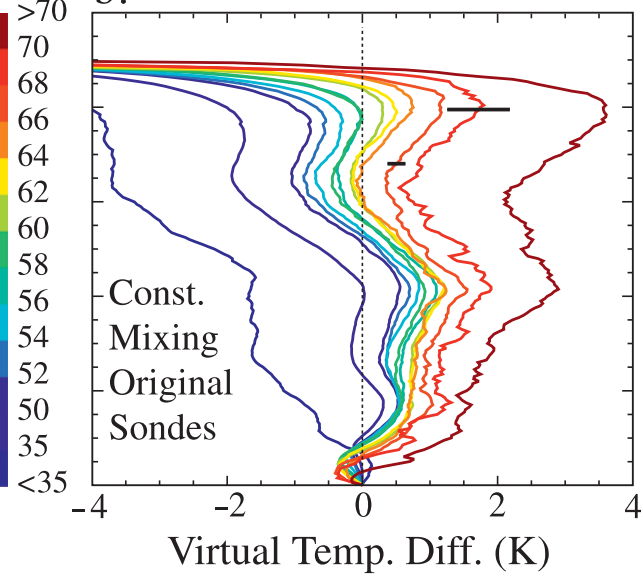

d.

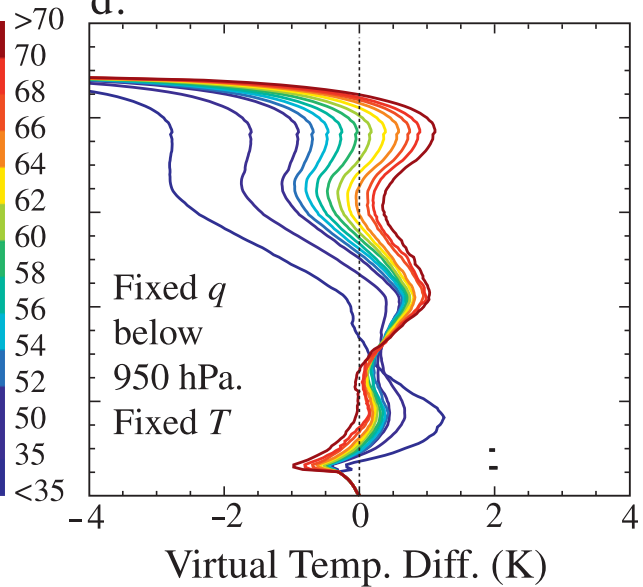

FIG. 7. Virtual temperature (K) difference profiles conditionally averaged on initial sonde column water vapor in $\mathrm{mm}$ (color bar), where the environmental (initial) sonde virtual temperature is subtracted from a profile determined by lifting a $1000-\mathrm{hPa}$ parcel conserving total water and liquid equivalent potential temperature but also including (a) no environmental mixing, (b) constant $0.5 \%$ mixing, (c) mixing with adjusted sonde profiles using mean specific humidity for levels above $950 \mathrm{hPa}$, and (d) mixing with an adjusted sonde profile using mean temperature for all levels and mean specific humidity for levels below $950 \mathrm{hPa}$. Horizontal bars indicate limits of the maximum, as well as a representative, standard error range below $150 \mathrm{hPa}$ [note that these bars appear on the side in (d) for visual clarity]. For a few sondes in (c) and (d), $q$ values have been slightly reduced at a few levels to remove supersaturation.

are based on constant entrainment as above but hold $q$ and/or temperature $T$ to constant (mean sonde) profiles in different layers. Figure $7 \mathrm{c}$ shows virtual temperature perturbation profiles for lifted parcels using a constant profile of $q$ above $950 \mathrm{hPa}$, with $T$ and subcloud $q$ unchanged. Most of the bins have a reduced buoyancy above the subcloud layer, showing the importance of relatively dry air being entrained by the plume (note again that most of the bins chosen have greater than average $\mathrm{CWV}$, since this is the transition region we are interested in). However, the subcloud layer moisture and $\theta_{e}$, which increase along with CWV, also have an important effect on the buoyancy, which is especially noticeable by the spread in the curves from about 950 to $600 \mathrm{hPa}$ despite the identical (weak) dry air entrainment (although this is compounded by the effect of $q$ on virtual temperature, as mentioned below). If $T$ is also held constant above $950 \mathrm{hPa}$ (not shown), there is an even larger spread throughout the troposphere, implying that tropospheric $T$ tends to increase with increasing $\mathrm{CWV}$, most likely as a result of convection. These increasing tropospheric temperatures offset the higher parcel buoyancies due to higher $\theta_{e}$ in the subcloud layer; this, plus the relatively dry air that has been entrained equally through the lower levels by all the plumes, explains the low amount of spread in the upper troposphere seen in Fig. 7c.

The results of an analysis that is converse to that of Fig. 7c, such that $T$ and $q$ are held to constant mean profiles except for $q$ above $950 \mathrm{hPa}$, which varies as in the 
original sondes, are shown in Fig. 7d. With nothing allowed to vary but the free-tropospheric moisture, there is a significant spread (as measured against standard errors) for mixed lifted parcels by the time they reach $400 \mathrm{hPa}$. The parcels mixing with the driest air, from the lowest CWV bins, reach negative buoyancy rapidly in the midtroposphere. The middle and higher bins show significant spread in the upper troposphere, and the top three bins are the only ones which remain positive above $400 \mathrm{hPa}$.

In the lower troposphere, without the compensating effects of higher moist static energy in the subcloud layer, the bins with larger tropospheric water actually show significantly lower buoyancy. This is because moist air is less dense than dry air of the same temperature; accordingly, all else being equal, parcels lifted into a drier environment are more buoyant (until they entrain enough dry air to lose their high moist static energy amounts). The effect of $q$ on virtual temperature also helps explain the large separation in the lower troposphere in Fig. 7c. Note that the curves in Fig. 7d are much smoother than in Figs. 7a-c: this is because the environmental temperature, the main component of environmental virtual temperature and the main contributor to the wiggles in the difference profiles, is held constant.

A test of buoyancy profiles conditionally averaged by precipitation rather than by CWV (not shown) showed less spread and less of a trend toward higher buoyancy values with higher precipitation. This is likely due to cold pools and other processes reducing subcloud layer $\theta_{e}$ during actual precipitation (indeed, the lack of trend was reduced when profiles were conditioned on precipitation occurring $3 \mathrm{~h}$ after the sonde launch). Another factor is that (as Fig. 1 shows) there is less spread in tropospheric water vapor when conditionally averaged on precipitation as opposed to CWV.

\section{Water vapor impact on buoyancy: Entrainment formulation and microphysics}

\section{a. Sensitivity to entrainment assumptions}

The above analysis makes clear that linear mixing (used under the same assumptions, such as neglect of freezing, for which the coefficient was tuned) can yield a transition to buoyant deep convective plumes at a CWV value corresponding to the pickup in precipitation. However, there are a number of ways in which constant mixing is unsatisfying. Jensen and Del Genio (2006) find that a significant range of constant entrainment values is necessary to reproduce cloud-top heights; Kuang and Bretherton (2006) estimate substantially larger values in
CSRM simulations, which if implemented in these soundings would not yield the right transition to deep convection.

Recent analysis of large-eddy simulations (LES) of convective boundary layers (Siebesma et al. 2007; de Roode et al. 2000; de Haij 2005) points toward a different dependence: a mixing coefficient proportional to $z^{-1}$, where $z$ is height, in the layer in which plume mass flux is growing. Here we argue that such entrainment arises naturally in plume models and leads to appealing consequences for thinking about the relative importance of different vertical layers. In particular, expressing the effects of entrainment in terms of a weighting function on environmental variables provides insight into why CWV provides a good index for buoyancy. The relationship to plume models is more succinct in $z$ coordinates, whereas the weighting function is simpler in pressure coordinates, so both are used. We then show sensitivity tests for two cases of such mixing. In section $5 \mathrm{~b}$ we discuss the sensitivity of the buoyancy analysis to microphysics assumptions.

\section{1) DEEP INFLOW ENTRAINMENT}

A standard continuity expression for updraft mass flux $m$ (Stommel 1947; Siebesma et al. 2007) is

$$
\frac{1}{m} \frac{\partial m}{\partial z}=\epsilon-\delta
$$

where $\epsilon$ and $\delta$ are the entrainment and detrainment rates, respectively. If a deep convective plume consists of increasing mass flux through the whole lower troposphere, assuming that entrainment is much greater than detrainment, then, following arguments dating back to Austin (1948), (2) implies large lower-tropospheric entrainment rates. Such deep inflow may be seen in observed core updraft velocity to about $5 \mathrm{~km}$ in Global Atmospheric Research Program (GARP) Atlantic Tropical Experiment (GATE) cumulonimbus (Fig. 5 of LeMone and Zipser 1980) and in CSRM-simulated updraft velocity up to about $6 \mathrm{~km}$ (Fig. 8 of Robe and Emanuel 1996). Here we seek simple examples that allow us to visualize the consequences of such "deep inflow" entrainment. This can provide a contrasting approximation to constant entrainment implementations such as that used in section $4 \mathrm{~b}$, which effectively assume a large entrainment rate ( $m$ increases from 0 to a finite value) through the first layer and then a much smaller rate of increase in subsequent layers. We further motivate these deep inflow entrainment cases by noting that they arise naturally from the argument first articulated by Houghton and Cramer (1951) that entrainment is necessitated by the increase of vertical velocity with height in a convective plume due to acceleration by buoyancy. 
Houghton and Cramer (1951) termed this "dynamic entrainment," although this term is also used to refer to ordered inflow, as opposed to turbulent entrainment (e.g., Ferrier and Houze 1989). For our purposes, the key effect is that the inflow to the plume remains substantial through a deep lower-tropospheric layer.

From (2), we can compute an entrainment coefficient for any mass flux profile if we neglect detrainment (Ogura and Cho 1973). We consider a family of mass flux profiles increasing smoothly from zero at low levels (and connecting to some other dependence in the midtroposphere):

$$
m \propto z^{\alpha} .
$$

An exponent $\alpha=1$ would be a linear increase in height, which might correspond to a lower-tropospheric response to a baroclinic wave or to an entraining plume under circumstances outlined below. An exponent $\alpha=1 / 2$ might correspond to the $z^{1 / 2}$ updraft velocities seen in dimensional arguments as early as Scorer (1957). In (2), this mass flux family yields

$$
\epsilon-\delta=\alpha z^{-1},
$$

which corresponds to the entrainment vertical dependence of Siebesma et al. (2007).

Entrainment effects on a conserved quantity in the plume (e.g., Siebesma et al. 2007) are given by

$$
\frac{\partial r}{\partial z}=\epsilon(\tilde{r}-r)
$$

For clarity we use $z$ coordinates here, although our computations will use the corresponding equation in pressure $(p)$ coordinates. Using (5) for potential temperature to diagnose entrainment rates in LES simulations of convective boundary layers (de Roode et al. 2000; de Haij 2005; Siebesma et al. 2007) led to an empirical fit for the mixing coefficient $\epsilon=c_{\epsilon} z^{-1}$, with $c_{\epsilon} \approx 0.4-0.55$ (Jakob and Siebesma 2003). For these boundary layer LES studies, $\epsilon$ can contain another term that has a maximum near the trade inversion (Siebesma et al. 2007), but we omit this for the present focus on low levels of a deep convective plume.

\section{2) RELATIONSHIP TO UPDRAFT VELOCITY EQUATION}

For additional justification, consider an updraft velocity equation (e.g., Siebesma et al. 2007):

$$
\frac{\partial w_{u}^{2}}{\partial z}=-\frac{c}{z} w_{u}^{2}+a B
$$

where $w_{u}$ is the updraft velocity, $B$ is the buoyancy term, and $c$ and $a$ are constants. The $z^{-1}$ in the first rhs term comes from assuming that $\epsilon$ has the form (4). The pressure term can be considered as part of $B$ or the coefficients depending on assumptions. Values of the coefficients will be unimportant to the results used here. A solution for this is

$$
w_{u}^{2}=z^{-c} \int_{0}^{z} a z^{c} B d z
$$

If $B$ does not vary strongly with height this gives $w_{u} \propto z^{1 / 2}$, which yields $c_{\epsilon}=\alpha=0.5$ (neglecting detrainment and assuming that density and plume area coverage do not change rapidly such that $m$ has approximately the same vertical dependence of $w_{u}$ ). This is close to the LES value for shallow convection (Siebesma et al. 2007; Jakob and Siebesma 2003), thus roughly explaining that value. If $B$ instead increases linearly with height, one obtains an updraft velocity that increases roughly linearly with height, $w_{u} \propto z$. Buoyancy profiles are of course more complex, but roughly linear increases may be seen above $0.6 \mathrm{~km}$ in simulated CSRM updrafts (Kuang and Bretherton 2006, their Fig. 5). We note that in Fig. 7 , for different CWV bins, the buoyancy through the lower troposphere can be increasing or relatively constant, and thus for sensitivity studies it is reasonable to use mixing coefficients motivated by each of these two cases.

\section{3) DeEP INFLOW MIXING CASES}

We thus choose two cases of mixing coefficient vertical dependence: Deep Inflow A corresponds to the Siebesma et al. (2007) LES-based dependence, and Deep Inflow B corresponds to an increase in mass flux that is linear at low levels, tapering in midtroposphere. If detrainment is neglected, these would correspond to an exponent $\alpha$ of 0.4 and 1, respectively, in (3) and (4) (with 0.4 found empirically as mentioned above). Where $z$ and $w$ are needed for calculations, we use the mean height and density over all sondes to convert to/from $p$ coordinates.

Specifically, for Deep Inflow A,

$$
\chi_{k}=c_{\epsilon} z_{k}^{-1} \Delta z
$$

where $\chi_{k}$ is the coefficient in (1) (which was held constant in the previous section), $\Delta z$ is a positive finite difference layer depth, and $c_{\epsilon}=0.4$.

For Deep Inflow B, we choose a lower-tropospheric $w_{u}$ profile that increases nearly linearly at low levels, namely a quarter sine wave in $z$ with zero at $1000 \mathrm{hPa}$ 
and maximum at $430 \mathrm{hPa}(7 \mathrm{~km})$. This roughly approximates the Robe and Emanuel (1996) updraft velocities and is loosely consistent with observational studies of convective regions (e.g., LeMone and Zipser 1980; Cifelli and Rutledge 1994; LeMone and Moncrieff 1994). Small variations of the $m$-profile shape have little overall effect, and the magnitude is irrelevant (although the level of maximum $w_{u}$ will determine where entrainment tapers off to zero). Mixing coefficients are computed from the $p$-coordinate version of (2), neglecting detrainment, using $\chi_{k}=-m^{-1}(\partial m / \partial p) \Delta p$, with $\Delta p$ defined to be positive. Below $900 \mathrm{hPa}$, where small mass flux requires caution in finite differencing, we use analytical results from (10) below, yielding $\chi_{k}=\left(p_{0}-\right.$ $\left.p_{k}\right)^{-1} \Delta p$. Above $430 \mathrm{hPa}$, where the mass flux no longer increases, entrainment is set to zero for simplicity.

\section{4) Vertical WEIGHTING OF ENVIRONMENTAL VALUES}

For a plume increasing from zero mass flux at pressure $p_{0}$ the value of conserved quantity $r$ within the plume at level $p$ is related to the environmental value $\tilde{r}$ by

$$
r(p)=\frac{1}{m(p)} \int_{p_{0}}^{p} \tilde{r} \frac{\partial m}{\partial \dot{p}} d \grave{p},
$$

from the $p$-coordinate version of (5) and neglecting detrainment in (2). The vertical rate of increase of mass gives the weighting of the environmental variable. For the case of a linearly increasing plume $m=c\left(p_{0}-p\right)$, this reduces to the vertical average over all levels below:

$$
r(p)=\left(p-p_{0}\right)^{-1} \int_{p_{0}}^{p} \tilde{r} d \dot{p} .
$$

Therefore, although $\epsilon$ and $\chi$ decrease rapidly above the surface, this linear case shows that this does not necessarily result in strong dependence on near-surface values. Equal increments of mass are brought into the plume at each level, and the apparent high entrainment is simply because the mass flux is small near the surface. This can also be thought of as plumes rising more slowly having more time for dilution, related to the Neggers et al. (2002) argument for modeling entrainment rates as the inverse of updraft velocity.

This linear case further makes clear why CWV is a very reasonable indicator of buoyancy for deep entraining plumes. For this mass-flux profile, midtropospheric buoyancy depends on the environmental water vapor vertically integrated through the lower troposphere, a quantity similar to $\mathrm{CWV}$.
This case with equal weighting is for $m$ linear in pressure; in the lower midtroposphere differences arise from a case linear in $z$, but these are small compared to the range of profiles under consideration here. Different mass flux profiles yield different vertical weighting. For instance, for $m \propto\left(p_{0}-p\right)^{\alpha}$, the weighting is $\left(p_{0}-\right.$ $p)^{\alpha-1}$, which weights lower levels more heavily (when $\alpha<1)$. Specifically,

$$
r(p)=\left(p_{0}-p\right)^{-\alpha} \alpha \int_{p}^{p_{0}}\left(p_{0}-\grave{p}\right)^{\alpha-1} \tilde{r}(\grave{p}) d \grave{p} .
$$

To provide a quick comparison of the weighted averages (10) and (11), consider the level at which $\tilde{r}$ has the same value as the weighted mean, for a linear decrease in the environmental variable. For (10), this equivalent level occurs halfway-that is, at an interval $\left(p_{0}-p\right) / 2$ above $p_{0}$. For (11) with $\alpha=1 / 2$, the equivalent level shifts only modestly, to $\left(p_{0}-p\right) / 3$ above $p_{0}$. If we consider instead a piecewise constant profile of $\tilde{r}$ with a value $r_{b}$ for $p>p_{b}$, and $r_{t}$ in the lower free troposphere, (11) yields a fraction of $r(p)$ of $\left[\left(p_{0}-p_{b}\right) /\left(p_{0}-p\right)\right]^{\alpha}$ contributed by the boundary layer $r_{b}$. For $\alpha=1$, contributions are proportional to layer depth, as seen in (10). For $\alpha=1 / 2$, the boundary layer receives a larger weighting than a free-tropospheric layer of the same depth, but the contribution of, say, a layer from 925-700 $\mathrm{hPa}$ would be equal to that of a boundary layer from 1000-925 hPa; for evaluation of buoyancy at midlevels, the contribution $925-500 \mathrm{hPa}$ would exceed that of the boundary layer.

Overall, even when the vertical mean is not the optimal weighting, environmental CWV will be a reasonable buoyancy estimator for any mass flux increasing through a deep lower-tropospheric layer, especially given the preponderance of $\mathrm{CWV}$-associated moisture variance occurring in the lower free troposphere.

\section{5) Sensitivity to DeEP INFLOW MiXING PROFILES}

Figures $8 \mathrm{a}$ and $8 \mathrm{~b}$ show entraining plume buoyancy profiles resulting from the Deep Inflow A and Deep Inflow B cases. Although these different mixing profiles show different values in Fig. 8 for the exact level of sign change (neutral buoyancy) for the different buoyancy profiles, the qualitative spread and order of the curves is not much different for these two mixing schemes or for those in the buoyancy profiles for the constant mixing in Fig. 7b. As in the constant mixing case, only the top few curves (corresponding to the precipitation pickup in Fig. 3b) are buoyant at certain levels (although the vertical levels for which this is true are lower in these latter two mixing cases - the inclusion of ice processes discussed in section $5 \mathrm{~b}$ below offers one explanation for this). There 

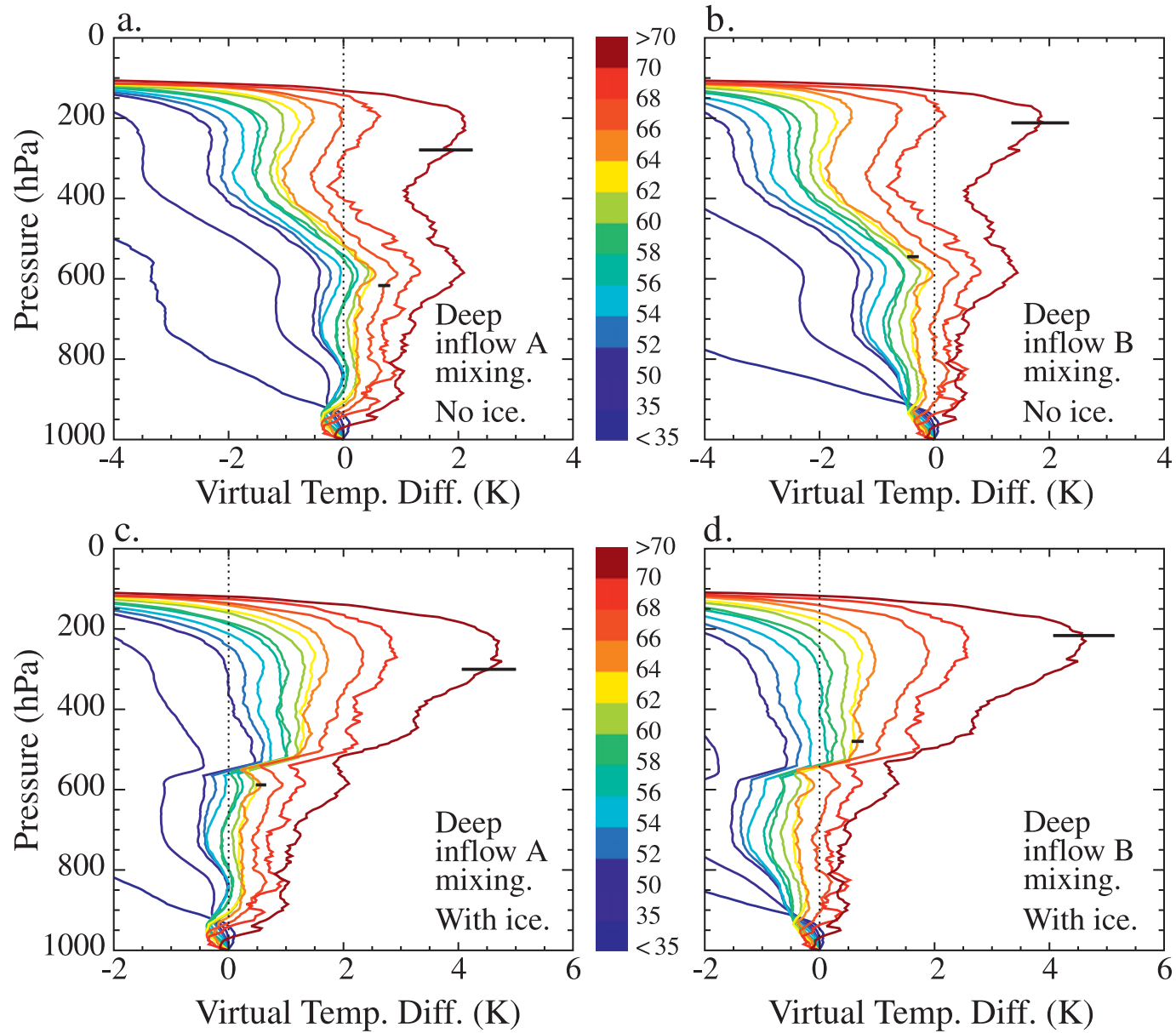

FIG. 8. Virtual temperature (K) difference profiles conditionally averaged on initial sonde column water vapor in $\mathrm{mm}$ (color bar), where the environmental (initial) sonde virtual temperature is subtracted from a profile determined by lifting a 1000-hPa parcel conserving total water and liquid equivalent potential temperature but also including: (a) Deep Inflow A mixing; (b) Deep Inflow B mixing; (c) Deep Inflow A mixing with conversion of liquid to ice, and following an ice-vapor reversible adiabat, above the freezing layer; and (d) as in (c), but for Deep Inflow B mixing. In (c) and (d), the jumps in virtual temperature difference at the freezing level for all but the uppermost and the two lowermost column water vapor bins have been extended from about $10-15 \mathrm{hPa}$ to $30 \mathrm{hPa}$, with a straight line connecting the otherwise original upper and lower curves, for visual clarity. Horizontal bars indicate limits of the maximum, as well as a representative, standard error range below $150 \mathrm{hPa}$.

is less sensitivity to $1000-\mathrm{hPa} \theta_{e}$ in these vertically dependent mixing cases, as should be expected given the greater emphasis placed on entraining lower-tropospheric air through a relatively deep layer.

For Deep Inflow B (Fig. 8b), few CWV bins have buoyant shallow cumulus plumes, but this is not surprising because strong entrainment occurs through the whole lower troposphere. For shallow cumulus, the Deep Inflow A profile-or the full LES-based mixing profile of Siebesma et al. (2007) — is likely more suitable.

Even more than the Deep Inflow A mixing scheme, the Deep Inflow B scheme places importance on all of the lower-tropospheric values, not just the subcloud layer. Because CWV captures variance throughout the lower free troposphere but includes contributions from the subcloud layer as well, CWV would be a good predictor of buoyancy if real mixing occurred as described by the deep inflow theory for locations that already have wind profiles typical of deep convection regions. As mentioned above, (10) results in equal weighting of all lower-tropospheric levels in the plume buoyancy, implying that $\mathrm{CWV}$, which weights many lower-tropospheric environmental moisture levels, should indeed be a good indicator of deep convection and precipitation.

\section{b. Sensitivity to microphysics assumptions}

An analysis of the sensitivity of the above buoyancy profiles to microphysics assumptions reveals a large 
amount of uncertainty in the specific values of buoyancy, although not in the monotonic order of the curves. Figures $8 \mathrm{c}$ and $8 \mathrm{~d}$ show the effects of including ice mixing above the freezing level for the Deep Inflow A and Deep Inflow B mixing schemes, respectively. The mixing process is similar to that used above, except that instead of conserving the liquid water potential temperature $\theta_{l}$, we instead conserve the ice-liquid water potential temperature $\theta_{i l}$ [Bryan and Fritsch 2004, their Eq. (23)]. This reduces to the reversible liquid water potential temperature used above (from Emanuel 1994) when there is no ice. To make the positive buoyancy contribution from freezing obvious, all liquid is converted to ice when the plume reaches $0^{\circ} \mathrm{C}$; this is the only irreversible process other than the mixing and is accomplished by equating the total enthalpies of all states before and after the freezing process (Emanuel 1994). This is presented as a limiting case that gives an upper bound on the impact of the freezing because no condensate is dropped out prior to freezing, and the freezing is done instantaneously. Implementing the phase change gradually between $0^{\circ}$ and $-40^{\circ} \mathrm{C}$ (e.g., Raymond and Blyth 1992; Bryan and Fritsch 2004) would spread this warming through a layer extending upward to about $250 \mathrm{hPa}$.

The curves including ice for the top CWV bins in Figs. $8 \mathrm{c}, \mathrm{d}$ are buoyant throughout the troposphere; in the Deep Inflow B case, only the top two CWV curves retain their buoyancy, although the third-highest bin becomes only slightly negatively buoyant from about 800-700 hPa. Buoyancy above the freezing level for plumes that are negatively buoyant below is unlikely to be realized in practice. Again, the Deep Inflow B mixing is not appropriate for shallow convection, as seen by the lack of shallow buoyant plumes in Fig. 8d. In both of these ice cases, there is still a large separation in the curves corresponding to CWV and a particularly noticeable separation between the top three bins and the lower ones, as discussed in previous figures. This again relates well to the precipitation pickup seen in Fig. 3. The constant mixing case, with freezing including, would not correspond well to this pickup because most bins would yield deep convection.

Another aspect of microphysics that affects the buoyancy values of mixing profiles is the treatment of hydrometeors, although Wei et al. (1998) found that entrainment was much more important than liquid water loading for updraft buoyancy in warm tropical oceanic convection. In all of the above analyses, all liquid and/or ice is retained in the mixed parcels (although of course $q_{t}$ is one of the mixed variables). Using a pseudoadiabatic entropy as the conserved variable above saturation (and thereby removing condensate and its effects on buoyancy) tends to increase the buoyancy by as much as $2 \mathrm{~K}$ in the midtroposphere, with lower increases above and below this, and with slight decreases at very high levels (not shown). This level of sensitivity to hydrometeor removal, as well as the sensitivity seen for ice processes above, is broadly consistent with the approximately 3-K differences seen in Raymond and Blyth (1992). Again, the order and separation of the curves is not affected much. The positive change comes from the removal of condensate loading in the virtual temperature calculation, whereas the reduction and eventual reversal of that change at upper levels reflects the lack of additional enthalpy transferred from condensate to air (Emanuel 1994). Although the removal of all condensate below the freezing level is unrealistic, above that level it is expected that some of the additional buoyancy gained from the removal of condensate could further increase the strength of updrafts.

\section{c. Sensitivity to column temperature and relative humidity}

The relationship between moisture and precipitation should depend on temperature. For this deep tropical location, temperature variations are small enough that they could be ignored to a first approximation. This was addressed in Figs. 2a and 4b, showing that most of the changes of $q$ associated with changes in CWV are due to changes in relative humidity, not changes in temperature.

A plausible next approximation might be to consider column relative humidity (the ratio of CWV to saturation CWV) following Bretherton et al. (2004). However, the rapid pickup in precipitation actually has a different temperature dependence (Neelin et al. 2008), occurring at a subsaturation that increases with temperature.

We examined both possibilities in the ARM sonde data. The analyses of Figs. 3, 7, and 8 were repeated (i) using column relative humidity and (ii) binning the data by $1000-200-\mathrm{hPa}$ column average temperature (with $1-\mathrm{K}$ width). The precipitation pickup occurred with similar magnitude to Fig. 3 for all cases, and the shifts as a function of temperature appeared consistent with those in Neelin et al. (2008), whereas normalization by saturation CWV caused overcompensation. However, the results of these analyses were noisy because of small sample size, even for bins only $1 \mathrm{~K}$ from the mean. Definitive results would require data through a larger range of temperatures. The buoyancy relationships were noisy as well, but the spread was similar to Fig. 7 .

\section{Conclusions}

Five years of radiosonde and precipitation gauge data from Nauru Island are used to examine the relationship 
of the vertical structure of water vapor to tropical deep convection. The leading vertical principal component of specific humidity, which is highly correlated with CWV, peaks in the lower troposphere around $800 \mathrm{hPa}$ and has a relatively small contribution from subcloud levels. The variances associated with CWV are due predominantly to fluctuations in relative humidity, not to changes in temperature at constant relative humidity. Although there is a larger average amount of partial CWV contained between the surface and $850 \mathrm{hPa}$ than there is above $850 \mathrm{hPa}$, nearly all CWV variance can be explained by the variance in the layer above $850 \mathrm{hPa}$. The boundary layer contains slightly more water vapor, but because it is tied closely to the surface by turbulent and convective processes, its variance is much smaller, and that smaller variance is itself correlated with the freetropospheric variance.

Moisture profiles conditionally averaged on precipitation show a strong association between rainfall and moisture variability in the free troposphere and little boundary layer variability. When precipitation is conditionally averaged on CWV, a sharp pickup occurs at high enough CWV, consistent with other observational studies (Bretherton et al. 2004; Peters and Neelin 2006). Furthermore, this same pickup can be reproduced by conditionally averaging precipitation only on the partial CWV from 850-200 hPa, while averaging only on subcloud-layer (below $950 \mathrm{hPa}$ ) water vapor shows little corresponding response in precipitation. This suggests that moisture above the boundary layer is the key component in the relationship between CWV and the transition to deep convection and higher average precipitation rates, at least over tropical ocean regions comparable to Nauru.

Because CWV is widely observed from satellite retrievals, we seek to understand why it proves to be such a useful indicator of favorable conditions for tropical deep convection. (In appendix A, the radiosonde analysis performed in this study is shown to be relevant to the $0.25^{\circ}$ latitude/longitude satellite footprint scales that have helped reveal the CWV-precipitation relationship.) The buoyancy of plumes rising under different conditions, for several entrainment assumptions, provides insight. The transition to high precipitation rates at sufficiently high CWV appears to depend primarily on free-tropospheric moisture, which can greatly affect the buoyancy of lifted parcels undergoing entrainment. There is also a dependence on the small but significant correlation of CWV and subcloud layer moisture and $\theta_{e}$.

Entraining plumes tend to be far more buoyant at middle and upper levels for profiles with larger CWV values. This is robust for all three mixing profiles analyzed, although the level at which positively buoyant parcels reach neutral buoyancy differs, as does the relative weighting of entrainment from the free troposphere and boundary layer. Constant mixing, similar to many convective parameterizations, must be rather small to not kill convection by the time it reaches the middle troposphere; it thus tends to emphasize boundary layer $\theta_{e}$. Using mixing values from Brown and Zhang (1997) can give the transition to deep convection at the approximate $\mathrm{CWV}$ value at which precipitation picks up, but only if freezing is neglected.

Two "deep-inflow" mixing profiles based on increasing mass flux through a deep lower-tropospheric layer are considered. One is based on LES studies of entrainment in convective boundary layers (Siebesma et al. 2007), and a second assumes entrainment associated with a mass flux profile increasing linearly at low levels and then tapering to a maximum at $430 \mathrm{hPa}$. Both yield an increase in buoyancy as a function of CWV. When simple freezing physics is included, the deep inflow mixing cases both give better correspondence than constant mixing between the pickup in precipitation in the upper few CWV bins and buoyancy available for deep convection. We note that these are presented as sensitivity tests that indicate directions to pursue in revising mixing parameterization and would require adaptation before use in a climate model.

Analytic results for these mixing profiles show how buoyancy in the midtroposphere depends on a weighted vertical average over the lower troposphere; in the case of a linearly growing plume, all lower-tropospheric levels are weighted equally. In the presence of such entrainment, CWV is thus a very reasonable measure of the buoyancy available to a deep convective plume.

These results underline the key role that freetropospheric moisture plays in the transition from shallow to deep convection. The observed pickup of precipitation with CWV is linked to increased buoyancy of entraining plumes, and the importance of accurately representing the entrainment process to obtain this sensitivity is shown. This adds an observational constraint on entrainment that may be useful in revising global climate model convective parameterizations and points toward entrainment schemes associated with more realistic mass flux profiles than the commonly used constant mixing.

Acknowledgments. This work was supported in part by National Science Foundation ATM-0082529 and National Oceanic and Atmospheric Administration NA05OAR4311134 and NA08OAR4310882. JDN acknowledges the John Simon Guggenheim Memorial Foundation and the National Center for Atmospheric Research for sabbatical support. CEH was supported 
by NASA Earth System Science Fellowship Grant NNX06AF83H. ARM data were used with the cooperation of the U.S. Department of Energy as part of the Atmospheric Radiation Measurement Program Climate Research Facility. We thank A. Del Genio, K. Emanuel, M. Hughes, B. Lesht, B. Medeiros, R. Neale, L. Nuijens, S. Sherwood, P. Siebesma, B. Stevens, J. Tribbia, X. Wu, and G. Zhang for helpful comments, K. Hales-Garcia for TMI data processing, and J. Meyerson for graphical assistance.

\section{APPENDIX A}

\section{Comparison between TMI Satellite CWV and Radiosonde CWV}

Because one motivation of this study is to investigate physical interpretations of statistical relationships between CWV and precipitation previously found using satellite data (Peters and Neelin 2006), we here compare ARM radiosonde CWV and TMI CWV centered at $0.625^{\circ} \mathrm{S}, 166.875^{\circ} \mathrm{E}$, near Nauru. The TMI data are at $0.25^{\circ} \times 0.25^{\circ}$ latitude/longitude resolution, from the Hilburn and Wentz (2008) algorithm; related microwave retrievals have been extensively validated (Wentz and Spencer 1998; Bretherton et al. 2004). To provide a sense of applicability of conclusions from radiosonde CWV to satellite data and potentially to parameterizations at various horizontal scales, averages over three grid sizes are examined. Values for two lower resolutions $\left(0.75^{\circ} \times 0.75^{\circ}\right.$ and $\left.1.25^{\circ} \times 1.25^{\circ}\right)$ are obtained by averaging all of the available data within the larger grid box for each satellite overpass, as long as the overpass at least includes data for the center grid point in the box. Times are assigned based on the center grid point. Each TMI CWV measurement is then matched to an ARM radiosonde if the satellite overpass occurred within $\pm 2 \mathrm{~h}$ of the sonde launch time.

Figure A1 shows the comparison for averages by TMI CWV bins that are the same as used in the text. Overall, the values are very similar. The points lie close to the $y=$ $x$ lines (which are vertically offset for the gray cases for visual clarity), almost always within one standard error of the mean. There are very few satellite CWV values above about $66 \mathrm{~mm}$, so the comparison is difficult to make there. However, when we use the same ARM precipitation gauge data from Nauru that we analyzed above and average within $\pm 30 \mathrm{~min}$. of the satellite CWV data, we can reproduce a pickup of precipitation near those same high bins (combined into one bin above $66 \mathrm{~mm}$ ) that we saw with the ARM sondes. We can also largely reproduce the same precipitation pickup using TMI precipitation sampled near the ARM sondes (not shown).

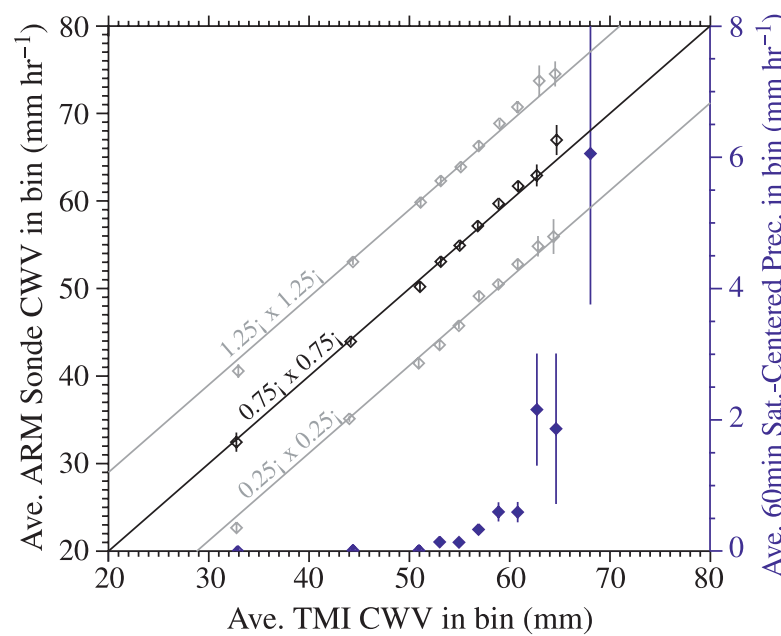

FIG. A1. ARM radiosonde CWV conditionally averaged on TMI satellite CWV taken at three different horizontal averaging resolutions. The gray lines and their associated data points have been offset vertically from their true positions, which are the same as the black line $y=x$. The blue filled diamonds show ARM precipitation gauge data averaged for $\pm 30 \mathrm{~min}$ centered at the TMI satellite $\mathrm{CWV}$ values, averaged at $0.75^{\circ} \times 0.75^{\circ}$ resolution. Vertical lines show standard errors for each bin mean. CWV bin widths are $<20,20-35,35-50$, then every $2 \mathrm{~mm}$ up to 66 , and $>66$. Bins with fewer than five counts (mainly the highest bin for CWV comparisons) are excluded.

\section{APPENDIX B}

\section{Convective Cloud-Top Height Conditioned on Column Water Vapor}

Previous studies suggest that the transitions we see in entraining plume buoyancy and precipitation are likely present in cloud-top height as well. Brown and Zhang (1997) tuned their constant entrainment profile to predict cloud-top height; Jensen and Del Genio (2006) found that cumulus congestus cloud-top heights at Nauru tend to be limited more by midtropospheric dryness than by freezing level stability. An observational product combining micropulse lidar and cloud radar to determine the height of convective clouds (Clothiaux et al. 2000) is available at Nauru, although the attenuation effects present at rainfall amounts above $5 \mathrm{~mm} \mathrm{~h}^{-1}$ (Jensen and Del Genio 2006) make the measurements problematic for the transition to very high rain rates of interest here. With this caveat, this appendix is included to provide a sense of how the precipitation pickup described in the text might relate to studies based on cloud-top height.

To test whether the precipitation pickup corresponds to a transition in cloud-top height, we find the highest heights for convective clouds (those with cloud base 


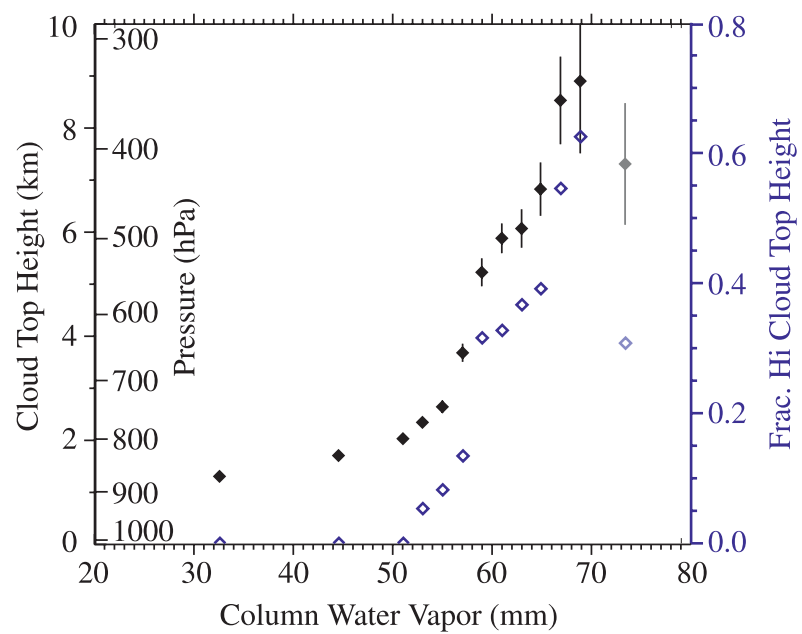

FIG. B1. Convective cloud-top height (black filled diamonds) and fraction of clouds with tops above $400 \mathrm{hPa}$ (open blue diamonds) conditionally averaged on column water vapor. Vertical lines show standard errors for each bin mean. CWV bin widths are $<20$, $20-35,35-50$, then every $2 \mathrm{~mm}$ up to 70 , and $>70$. The highest CWV bin values are lighter shades to show likely attenuation.

below $2 \mathrm{~km}$ ) within \pm 30 min of each radiosonde launch time. We then conditionally average these maximum heights by CWV (Fig. B1, black filled diamonds). These values roughly show the three main convective cloud types found by Johnson et al. (1999): shallow cumulus, congestus, and cumulonimbus. Our precipitation pickup (which occurs above about $66 \mathrm{~mm} \mathrm{CWV}$ ) appears to correspond to a transition from conditions where the highest clouds are congestus to conditions where cumulonimbus are common, although the average highest cloud-top heights are still far below the tropopause in this estimate. This apparent underestimation is likely due to attenuation of lidar and radar as the average rainfall increases, and the last bin is especially suspect for this reason and is therefore shaded in gray. We also show the fraction of these maximum cloud-top heights that are above $400 \mathrm{hPa}$, again as an indication of deep convection (and again shading the last bin a lighter color because of likely attenuation effects). The other transition evident in Fig. B1, from shallow cumulus to congestus occurring just below the 60-mm CWV bin, corresponds to the slow increase in precipitation averages evident around those CWV bins in Fig. 3b.

\section{REFERENCES}

Austin, J. M., 1948: A note on cumulus growth in a nonsaturated environment. J. Meteor., 5, 103-107.

Bechtold, P., M. Köhler, T. Jung, F. Doblas-Reyes, M. Leutbecher, M. J. Rodwell, F. Vitart, and G. Balsamo, 2008: Advances in simulating atmospheric variability with the ECMWF model: From synoptic to decadal time-scales. Quart. J. Roy. Meteor. Soc., 134, 1337-1351, doi:10.1002/qj.289.
Biasutti, M., A. H. Sobel, and Y. Kushnir, 2006: AGCM precipitation biases in the tropical Atlantic. J. Climate, 19, 935-958.

Bretherton, C. S., M. E. Peters, and L. E. Back, 2004: Relationships between water vapor path and precipitation over the tropical oceans. J. Climate, 17, 1517-1528.

Brown, R. G., and C. Zhang, 1997: Variability of midtropospheric moisture and its effect on cloud-top height distribution during TOGA COARE. J. Atmos. Sci., 54, 2760-2774.

Bryan, G. H., and J. M. Fritsch, 2004: A reevaluation of ice-liquid water potential temperature. Mon. Wea. Rev., 132, 2421-2431.

Cifelli, R., and S. Rutledge, 1994: Vertical motion structure in Maritime Continent mesoscale convective systems: Results from a 50-MHz profiler. J. Atmos. Sci., 51, 2631-2652.

Clothiaux, E. E., T. P. Ackerman, G. G. Mace, K. P. Moran, R. T. Marchand, M. A. Miller, and B. E. Martner, 2000: Objective determination of cloud heights and radar reflectivities using a combination of active remote sensors at the ARM CART sites. J. Appl. Meteor., 39, 645-665.

Dai, A., 2006: Precipitation characteristics in eighteen coupled climate models. J. Climate, 19, 4605-4630.

de Haij, M. J., 2005: Evaluation of a new trigger function for cumulus convection. KNMI Tech. Rep. TR-276, 117 pp.

DeMott, C. A., and S. Rutledge, 1998: The vertical structure of TOGA COARE convection. Part II: Modulating influences and implications for diabatic heating. J. Atmos. Sci., 55, 2748-2762.

Derbyshire, S. H., I. Beau, P. Bechtold, J.-Y. Grandpeix, J.-M. Piriou, J.-L. Redelsperger, and P. M. M. Soares, 2004: Sensitivity of moist convection to environmental humidity. Quart. J. Roy. Meteor. Soc., 130, 3055-3079.

de Roode, S. R., P. G. Duynkerke, and A. P. Siebesma, 2000: Analogies between mass-flux and Reynolds-averaged equations. J. Atmos. Sci., 57, 1585-1598.

Emanuel, K. A., 1994: Atmospheric Convection. 1st ed. Oxford University Press, $580 \mathrm{pp}$.

Ferrier, B. S., and R. A. Houze Jr., 1989: One-dimensional timedependent modeling of GATE cumulonimbus convection. J. Atmos. Sci., 46, 330-352.

Grabowski, W. W., 2003: MJO-like coherent structures: Sensitivity simulations using the cloud-resolving convection parameterization (CRCP). J. Atmos. Sci., 60, 847-864.

- 2006: Impact of explicit atmosphere-ocean coupling on MJO-like coherent structures in idealized aquaplanet simulations. J. Atmos. Sci., 63, 2289-2306.

Hilburn, K. A., and F. J. Wentz, 2008: Intercalibrated passive microwave rain products from the Unified Microwave Ocean Retrieval Algorithm (UMORA). J. Appl. Meteor. Climatol., 47, 778-794.

Holloway, C. E., and J. D. Neelin, 2007: The convective cold top and quasi equilibrium. J. Atmos. Sci., 64, 1467-1487.

Houghton, H. G., and H. E. Cramer, 1951: A theory of entrainment in convective currents. J. Meteor., 8, 95-102.

Jakob, C., and A. P. Siebesma, 2003: A new subcloud model for mass-flux convection schemes: Influence on triggering, updraft properties, and model climate. Mon. Wea. Rev., 131, 2765-2778.

Jensen, M. P., and A. D. Del Genio, 2006: Factors limiting convective cloud-top height at the ARM Nauru Island climate research facility. J. Climate, 19, 2105-2117.

Johnson, R. H., T. M. Rickenbach, S. Rutledge, P. Ciesielski, and W. Schubert, 1999: Trimodal characteristics of tropical convection. J. Climate, 12, 2397-2418.

Kuang, Z., and C. S. Bretherton, 2006: A mass-flux scheme view of a high-resolution simulation of a transition from shallow to deep cumulus convection. J. Atmos. Sci., 63, 1895-1909. 
LeMone, M. A., and E. J. Zipser, 1980: Cumulonimbus vertical velocity events in GATE. Part I: Diameter, intensity, and mass flux. J. Atmos. Sci., 37, 2444-2457.

—_, and M. W. Moncrieff, 1994: Momentum and mass transport by convective bands: Comparisons of highly idealized dynamical models to observations. J. Atmos. Sci., 51, 281-305.

Lintner, B. R., and J. D. Neelin, 2008: Eastern margin variability of the South Pacific convergence zone. Geophys. Res. Lett., 35, L16701, doi:10.1029/2008GL034298.

Liu, W. T., W. Tang, and P. P. Niiler, 1991: Humidity profiles over the ocean. J. Climate, 4, 1023-1034.

Malkus, J. S., 1954: Some results of a trade-cumulus cloud investigation. J. Meteor., 11, 220-237.

Mapes, B. E., and P. Zuidema, 1996: Radiative-dynamical consequences of dry tongues in the tropical troposphere. J. Atmos. Sci., 53, 620-638.

— S. Tulich, J. Lin, and P. Zuidema, 2006: The mesoscale convection life cycle: Building block or prototype for largescale tropical waves? Dyn. Atmos. Oceans, 42, 3-29.

Mather, J. H., T. P. Ackerman, W. E. Clements, F. J. Barnes, M. D. Ivey, L. D. Hatfield, and R. M. Reynolds, 1998: An atmospheric radiation and cloud station in the tropical western Pacific. Bull. Amer. Meteor. Soc., 79, 627-642.

Neale, R. B., J. H. Richter, and M. Jochum, 2008: The impact of convection on ENSO: From a delayed oscillator to a series of events. J. Climate, 21, 5904-5924.

Neelin, J. D., 1997: Implications of convective quasi-equilibrium for the large-scale flow. The Physics and Parameterization of Moist Atmospheric Convection, Kluwer Academic, 413-416.

—_, and N. Zeng, 2000: A quasi-equilibrium tropical circulation model-Formulation. J. Atmos. Sci., 57, 1741-1766.

- C. Chou, and H. Su, 2003: Tropical drought regions in global warming and El Niño teleconnections. Geophys. Res. Lett., 30, 2275, doi:10.1029/2003GL018625.

_ - M. Münnich, H. Su, J. E. Meyerson, and C. E. Holloway, 2006: Tropical drying trends in global warming models and observations. Proc. Natl. Acad. Sci. USA, 103, 6110-6115.

— O O. Peters, J. W.-B. Lin, K. Hales, and C. E. Holloway, 2008: Rethinking convective quasi-equilibrium: Observational constraints for stochastic convective schemes in climate models. Philos. Trans. Roy. Soc. London, A366, 2851-2604.

Neggers, R. A. J., A. P. Siebesma, and H. J. J. Jonker, 2002: A multiparcel model for shallow cumulus convection. J. Atmos. Sci., 59, 1655-1668.

— J. D. Neelin, and B. Stevens, 2007: Impact mechanisms of shallow cumulus convection on tropical climate dynamics. J. Climate, 20, 2623-2642.

Nuijens, L., B. Stevens, and A. P. Siebesma, 2009: The environment of precipitating shallow cumulus convection. J. Atmos. Sci., in press.

Numaguti, A., R. Oki, K. Nakamura, K. Tsuboki, N. Misawa, T. Asai, and Y.-M. Kodama, 1995: 4-5-day-period variation on low-level dry air observed in the equatorial western Pacific during the TOGA-COARE IOP. J. Meteor. Soc. Japan, 73, 267-290.

Ogura, Y., and H.-R. Cho, 1973: Diagnostic determination of cumulus cloud populations from observed large-scale variables. J. Atmos. Sci., 30, 1276-1286.

Parsons, D. B., K. Yoneyama, and J.-L. Redelsperger, 2000: The evolution of the tropical western Pacific atmosphere-ocean system following the arrival of a dry intrusion. Quart. J. Roy. Meteor. Soc., 126, 517-548.

Peters, O., and J. D. Neelin, 2006: Critical phenomena in atmospheric precipitation. Nature Phys., 2, 393-396.
Raymond, D. J., 1997: Boundary layer quasi-equilibrium (BLQ). The Physics and Parameterization of Moist Atmospheric Convection, R. K. Smith, Ed., Kluwer Academic, 387-397.

- 2000: Thermodynamic control of tropical rainfall. Quart. J. Roy. Meteor. Soc., 126, 889-898.

— model to cumulonimbus clouds. J. Atmos. Sci., 49, 1968-1983.

Robe, F. R., and K. A. Emanuel, 1996: Moist convective scaling: Some inferences from three-dimensional cloud ensemble simulations. J. Atmos. Sci., 53, 3265-3275.

Scorer, R. S., 1957: Experiments on convection of isolated masses of buoyant fluid. J. Fluid Mech., 2, 583-594.

Sherwood, S. C., 1999: Convective precursors and predictability in the tropical western Pacific. Mon. Wea. Rev., 127, 2977-2991.

_ convective events and their environment. Mon. Wea. Rev., 127, 1777-1795.

— , P. Minnis, and M. McGill, 2004: Deep convective cloud-top heights and their thermodynamic control during CRYSTALFACE. J. Geophys. Res., 109, D20119, doi:10.1029/2004JD004811. , E. R. Kursinski, and W. G. Read, 2006: A distribution law for free-tropospheric relative humidity. J. Climate, 19, 6267-6277.

Siebesma, A. P., P. M. M. Soares, and J. Teixeira, 2007: A combined eddy-diffusivity mass-flux approach for the convective boundary layer. J. Atmos. Sci., 64, 1230-1248.

Slingo, J. M., and Coauthors, 1996: The intraseasonal oscillation in 15 atmospheric general circulation models: Results from an AMIP diagnostic subproject. Climate Dyn., 12, 325-357.

Sobel, A. H., and J. D. Neelin, 2006: The boundary layer contribution to intertropical convergence zones in the quasiequilibrium tropical circulation model framework. Theor. Comput. Fluid Dyn., 20, 323-350.

— S. E. Yuter, C. S. Bretherton, and G. N. Kiladis, 2004: Largescale meteorology and deep convection during TRMM KWAJEX. Mon. Wea. Rev., 132, 422-444.

Stokes, G. M., and S. E. Schwartz, 1994: The Atmospheric Radiation Measurement (ARM) program: Programmatic background and design of the cloud and radiation testbed. Bull. Amer. Meteor. Soc., 75, 1201-1221.

Stommel, H., 1947: Entrainment of air into a cumulus cloud. J. Meteor., 4, 91-94.

Tompkins, A. M., 2001a: Organization of tropical convection in low vertical wind shears: The role of cold pools. J. Atmos. Sci., 58, 1650-1672.

-, 2001b: Organization of tropical convection in low vertical wind shears: The role of water vapor. J. Atmos. Sci., 58, 529-545.

Wei, D., A. M. Blyth, and D. J. Raymond, 1998: Buoyancy of convective clouds in TOGA COARE. J. Atmos. Sci., 55, 3381-3391.

Wentz, F. J., and R. W. Spencer, 1998: SSM/I rain retrievals within a unified all-weather ocean algorithm. J. Atmos. Sci., 56, 1613-1627.

Westwater, E. R., B. B. Stankov, D. Cimini, Y. Han, J. A. Shaw, B. M. Lesht, and C. N. Long, 2003: Radiosonde humidity soundings and microwave radiometers during Nauru99. J. Atmos. Oceanic Technol., 20, 953-971.

Xu, K.-M., and K. A. Emanuel, 1989: Is the tropical atmosphere conditionally unstable? Mon. Wea. Rev., 117, 1471-1479.

Yoneyama, K., 2003: Moisture variability over the tropical western Pacific Ocean. J. Meteor. Soc. Japan, 81, 317-337.

Zhang, G. J., and H. Wang, 2006: Toward mitigating the double ITCZ problem in NCAR CCSM3. Geophys. Res. Lett., 33, L06709, doi:10.1029/2005GL025229. 